ARTICLE

DOI: $10.1038 /$ s41467-018-07175-0

\title{
Oestrogen receptor $\alpha$ AF-1 and AF-2 domains have cell population-specific functions in the mammary epithelium
}

\author{
Stéphanie Cagnet ${ }^{1}$, Dalya Ataca (10 ${ }^{1}$, George Sflomos ${ }^{1}$, Patrick Aouad ${ }^{1}$, Sonia Schuepbach-Mallepell ${ }^{2}$, \\ Henry Hugues ${ }^{3}$, Andrée Krust ${ }^{4}$, Ayyakkannu Ayyanan ${ }^{1}$, Valentina Scabia ${ }^{1}$ \& Cathrin Brisken (1) ${ }^{1}$
}

Oestrogen receptor $\alpha(E R \alpha)$ is a transcription factor with ligand-independent and liganddependent activation functions (AF)-1 and -2. Oestrogens control postnatal mammary gland development acting on a subset of mammary epithelial cells (MECs), termed sensor cells, which are ER $\alpha$-positive by immunohistochemistry (IHC) and secrete paracrine factors, which stimulate ER $\alpha$-negative responder cells. Here we show that deletion of AF-1 or AF-2 blocks pubertal ductal growth and subsequent development because both are required for expression of essential paracrine mediators. Thirty percent of the luminal cells are ER $\alpha$-negative by IHC but express Esr1 transcripts. This low level ER $\alpha$ expression through AF-2 is essential for cell expansion during puberty and growth-inhibitory during pregnancy. Cell-intrinsic ER $\alpha$ is not required for cell proliferation nor for secretory differentiation but controls transcript levels of cell motility and cell adhesion genes and a stem cell and epithelial mesenchymal transition (EMT) signature identifying $\mathrm{ER} \alpha$ as a key regulator of mammary epithelial cell plasticity.

\footnotetext{
${ }^{1}$ Swiss Institute for Experimental Cancer Research, School of Life Sciences, Ecole Polytechnique Fédérale de Lausanne, CH-1015 Lausanne, Switzerland. ${ }^{2}$ Department of Biochemistry, University of Lausanne, CH-1066 Epalinges, Switzerland. ${ }^{3}$ Centre Hospitalier Universitaire Vaudois, Department of Laboratory Medecine, University Hospital of Lausanne, CH-1011 Lausanne, Switzerland. ${ }^{4}$ Institut de Génétique et de Biologie Moléculaire et Cellulaire (CNRS UMR7104; INSERM U596; ULP, Collège de France) and Institut Clinique de la Souris, Illkirch, Strasbourg, France. These authors contributed equally: Stéphanie Cagnet, Dalya Ataca, George Sflomos. Correspondence and requests for materials should be addressed to C.B. (email: cathrin.brisken@epfl.ch)
} 
O estrogens, $17 \beta$-estradiol (E2) and its metabolites, are pivotal for the development and the physiology of the breast and impinge on breast carcinogenesis. The oestrogen receptor a (ER $\alpha)$ is expressed in $40 \%$ of the luminal cells that make up the inner layer of the mammary epithelium surrounded by basal/myoepithelial cells ${ }^{1}$. Oestrogens drive pubertal development in the mouse mammary gland and induce expression of the progesterone receptor (PgR), activation of which drives cell proliferation during subsequent oestrous cycling and pregnancy. Both hormones rely on paracrine factors to activate stem cells and induce proliferation of other mammary epithelial cells (MECs) ${ }^{2}$.

The ERa belongs to the nuclear receptor family and is composed of six modular domains, namely, $A$ to $F^{3}$. Ligandindependent and ligand-dependent activation functions, AF-1 and AF-2 map to the A/B and E domains, respectively ${ }^{4,5}$. Ligandindependent signalling results from phosphorylation of different serine residues in AF- 1 by for instance $\mathrm{MAPK}^{6}, \mathrm{GSK}^{-} 3^{7}$ or cyclinA/cdk $2^{8}$. Upon activation, the receptor dimerises and translocates to the nucleus where it interacts either directly with the DNA via specific DNA sequences known as the oestrogen response elements, or indirectly via DNA-binding proteins like AP- $1{ }^{9}$. Full ligand-dependent transcriptional activity relies on synergistic activities of AF-1 and AF- $2^{5}$. A small fraction of the $\mathrm{ER} \alpha$ is found at the plasma membrane; it elicits rapid, nongenomic responses, which modulate multiple signalling pathways and create cross-talk between membrane and nuclear ERa ${ }^{10}$.

More than $70 \%$ of all breast cancers express the ERa and this is exploited therapeutically. The most widely used agent, tamoxifen, antagonises AF- $2^{11}$ and agonises AF- $1^{12}$, and is used in primary and secondary breast cancer prevention. Most insights into the molecular mechanisms underlying $\mathrm{ERa}$ signalling stem from in vitro studies with ERa-positive $(\mathrm{ER} \alpha+)$ breast cancer cell lines, in particular MCF-7 cells which express very high levels of the receptor and are exquisitely sensitive to E2. How ER signalling occurs in vivo in normal and cancerous tissue is poorly understood. To dissect the different aspects of ERa signalling in vivo, mice lacking specifically the AF-1 domain $\left(A F-1^{0}\right)^{13}$ or the AF-2 domain $\left(E R \alpha A F-2^{0}\right)^{14}$ were generated and compared to mice lacking the entire $\mathrm{ER} \alpha\left(E R \alpha^{--}\right)$; all three strains are viable but have impaired reproductive functions, and distinct organ defects $^{13-15}$. The role of the AF- 1 and the AF- 2 domains in the mammary epithelium was not analysed. Using $E R \alpha^{-/-}$mice, we have previously shown that ER $\alpha$ is required for ductal elongation in the mammary epithelium ${ }^{16}$.

Here, we explore the role of AF-1 and AF-2 vs. intact ERa signalling in mammary gland development; we demonstrate differential roles that are dependent on cell type and/or ERa protein levels and uncover important functions of the ERa in apparently ERa-luminal responder cells.

\section{Results}

Mammary gland development in ERaAF-1 ${ }^{0}$ and ERaAF-2 mice. To assess the impact of germ-line deletion of ERa liganddependent, AF-2, vs. ligand-independent, AF-1, genomic actions on mammary gland development, we analysed mammary glands of $A F-1^{0}$ and $A F-2^{0}$ females and their respective $W T$ littermates (Fig. 1a) at critical developmental stages using whole-mount stereomicroscopy (Fig. 1b, Supplementary Figure 1a-d). Before the onset of ovarian function, on postnatal day 21 , all females had rudimentary ductal systems (Supplementary Figure 1a) with on average $4.7 \%$ fat pad filling in $W T$ and $<3 \%$ fat pad filling in the ERa mutant littermates (Fig. 1c, Supplementary Figure 1a). In pubertal, that is 4- to 7-week-old WT females, rapidly growing ductal tips enlarged to form terminal end buds (TEBs) and ducts extended beyond the sub-iliac lymph node to fill $61 \%$ of the fat pad (Fig. 1b, c). In $A F-1^{0}$ and $A F-2^{0}$ littermates, no TEBs were found and fat pad filling remained $<3 \%$ (Fig. 1 b, c). In adult, 8 - to 12 -week-old $W T$ females, fat pads were filled up to $80 \%$, in their $A F-1^{0}$ and $A F-2^{0}$ littermates to $5.1 \%$ and $3 \%$ only, respectively (Fig. 1c, Supplementary Figure 1b). In older WT females, which have been exposed to repeated oestrous cycle related peaks of E2 and progesterone, side branching occurred (Supplementary Figure 1c, d; Fig. 1c) whereas the block of ductal growth persisted in $A F-2^{0}$ females (Supplementary Figure $1 \mathrm{~b}, \mathrm{c}$ ) as observed in $E R \alpha^{-1-}$ females $^{16}$. In older $A F-1^{0}$ females, few ducts occasionally extended beyond the lymph node (Supplementary Figure 1c, d, Fig. 1c). Mutant ducts were atrophic with decreased ductal diameters (Supplementary Figure 1c, d) but structurally intact with luminal and basal cell layers as revealed by histological analysis (Supplementary Figure 1e). Immunohistochemistry (IHC) revealed expression of ER $\alpha$ protein in $A F-1^{0}$ and $A F-2^{0}$ mammary epithelia at levels comparable to $W T$ controls (Fig. 1d), as reported for their uteri ${ }^{13,14}$. This excluded the possibility that the mutant ERa proteins were unstable and their expression in MECs was reduced or lost. Thus, the phenotypes reflect the specific deletions of AF-1 or AF-2 domain and show that both are required for ERa function during ductal elongation.

Endocrine disturbances in $\boldsymbol{A F - 1 ^ { 0 }}$ and $\boldsymbol{A F - 2 ^ { 0 }}$ mice. Adult $A F-1^{0}$, $A F-2^{0}$ and $E R \alpha^{-I-}$ female mice were reported to have increased serum levels of E2, luteinizing hormone and testosterone as measured by radioimmunoassay ${ }^{17}$. Our finding that mammary gland development was already affected before puberty begged the question whether endocrine disturbances may occur earlier. As plasma steroid hormone levels are very low prior to puberty, we used liquid chromatography tandem-mass spectrometry (LC-MS). We confirmed that both E2 and testosterone levels increased significantly in all three mutants in adulthood. E2 was detected at levels of $12 \mathrm{pg} / \mathrm{ml}$ in plasma of $W T$ females and increased almost 2-fold in $A F-1^{0}$ and threefold in $A F-2^{0}$ and $E R \alpha^{-/-}$females. Testosterone levels raised from on average $0.1 \mathrm{ng} / \mathrm{ml}$ in plasma of $W T$ females to $0.7 \mathrm{ng} / \mathrm{ml}$ plasma levels in $A F-1^{0}, 1.5 \mathrm{ng} / \mathrm{ml}$ in $A F-2^{0}$ and $1.4 \mathrm{ng} / \mathrm{ml}$ in $E R \alpha^{-/-}$ females (Fig. 2a). Plasma progesterone levels varied in $W T$ females due to oestrous cycling not observed in the mutants in which ovarian cycles are not established. All three mutants had decreased 11-deoxycorticosterone levels while 17-OH-progesterone levels were increased in $E R \alpha^{-1-}$ females (Fig. 2a).

Progesterone levels increased specifically in peripubertal $A F-2^{0}$ females whereas androstenedione levels increased in peripubertal $E R \alpha^{-1-}$ and pubertal $A F-2^{0}$ females (Fig. 2a). Testosterone was significantly increased in peripubertal $A F-1^{0}$ females. Hence, complex alterations of the endocrine milieu occurred already before and during puberty.

An overall analysis of the average fold-changes in steroid levels in $E R \alpha$ mutants compared to $W T$ and heterozygous littermates in relation to their biosynthetic pathways revealed comparable decrease of plasma levels of the progesterone derivatives, 11deoxycorticosterone and corticosterone, in all mutants in adulthood (Fig. 2b). The levels of E2 and its precursors $17 \mathrm{OH}$ progesterone, androstenedione, and testosterone, were close to $W T$ levels in $A F-1^{0}$ mice but deviated similarly in $E R \alpha^{-1-}$ and $A F-2^{0}$ females are in line with negative feedback loops of the E2 biosynthetic pathway being regulated by ligand-dependent ER activity.

Mammary epithelial-intrinsic role of AF-1 and AF-2 domains. The systemic effects of the germ-line mutations and the resulting complex endocrine abnormalities confounded the interpretation of the mammary gland phenotype. To assess the MEC intrinsic 

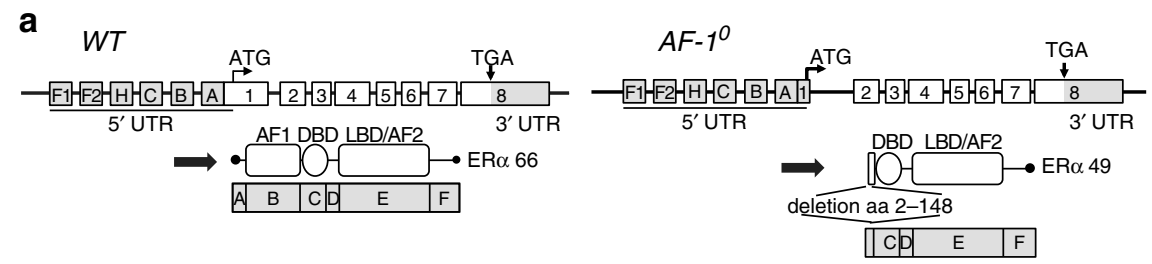

b
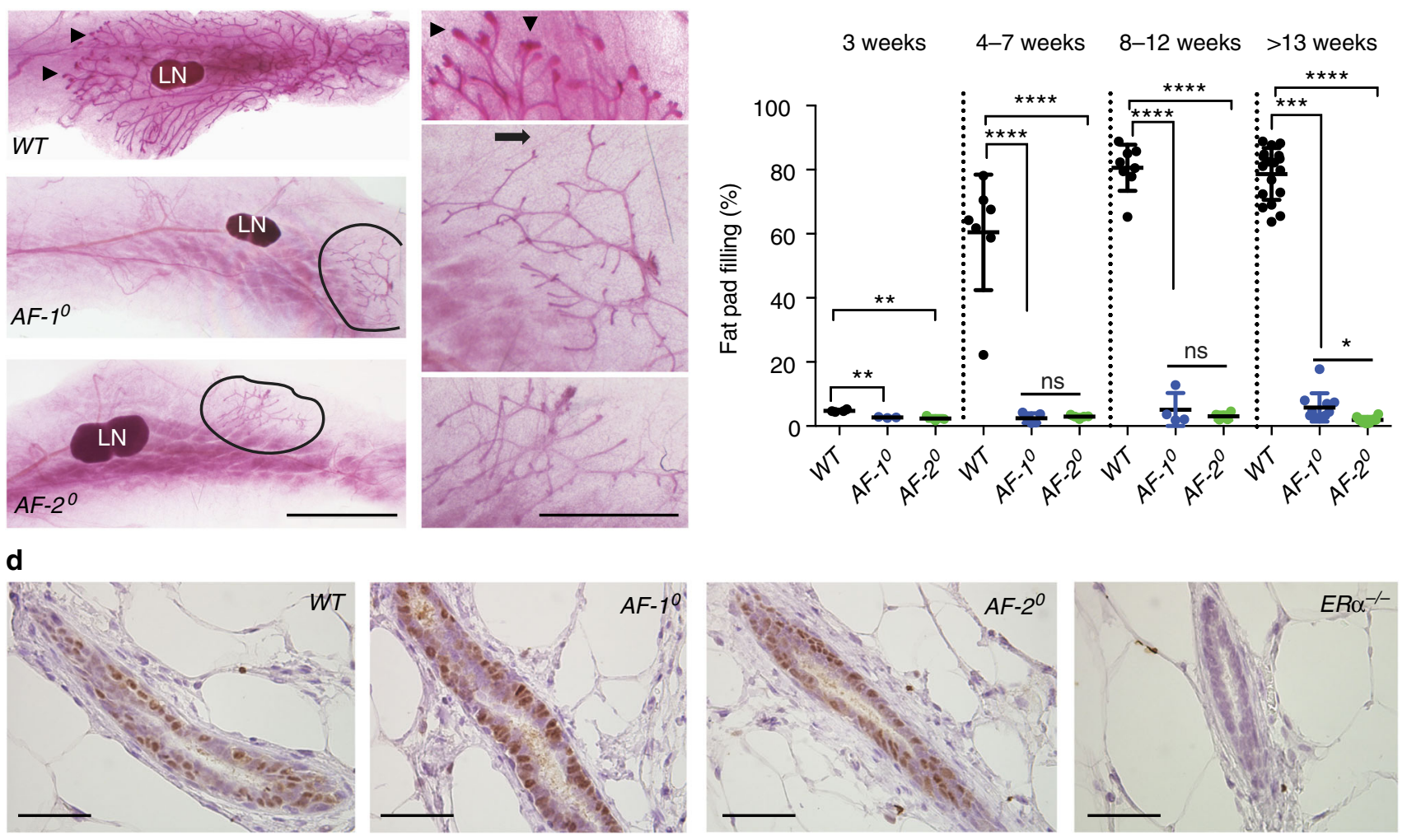

Fig. 1 Mammary gland phenotype of $A F-1^{0}$ and $A F-2^{0}$ mice. a Schematic representation of the mutant genomic loci and the ER $\alpha$ proteins expressed in WT mice, AF- 70 mice with deletion of amino acids 2-148, and AF-20 mice with deletion of amino acids 543-549. Only the main protein initiated by the translational initiation codon in exon 1 on amino acid 1 (ATG) is shown for each genotype. The less abundantly expressed protein is initiated in exon 2 on amino acid 178. b Whole-mount stereomicrographs of inguinal mammary glands from 7 -week-old $W T$, AF- $7^{0}$ and $A F-2^{0}$ females. Arrowheads indicate TEBs. Black lines mark the borders of the ductal outgrowth. Scale bars: $5 \mathrm{~mm}$ (left), $2 \mathrm{~mm}$ (right). LN sub-iliac lymph node. c Dot plot showing extent of fat pad area filled by the engrafted $W T, A F-1^{0}$ and $A F-2^{0}$ epithelia at different developmental stages $(n=3-18)$. Shown are means \pm SEM; unpaired, two-tailed, Student's $t$ test, ${ }^{\star} p<0.05,{ }^{\star \star} p<0.01,{ }^{\star \star \star} p<0.001,{ }^{\star \star \star \star} p<0.0001$, n.s. not significant. d ER $\alpha$ IHC of mammary glands from 3-week-old WT, AF- ${ }^{0}, A F-2^{0}$ and $E R \alpha^{-/-}$mice. Representative pictures of glands analysed from three females of each genotype are shown. Scale bar: $100 \mu \mathrm{m}$

requirement of each domain, we grafted fragments of ducts from $A F-1^{0} . G F P^{+}$or $A F-2^{0} . G F P^{+}$and WT.GFP ${ }^{+}$littermates into contralateral inguinal mammary glands of 3-week-old WT hosts surgically divested of endogenous epithelium ${ }^{18}$. Fluorescence stereomicroscopy of the engrafted glands 10 weeks after surgery showed that grafted WT epithelia filled the fat pads (Fig. 3a, e) but the $A F-1^{0} . G F P^{+}$fragments failed to grow (Fig. $3 \mathrm{~b}$, e). During pregnancy, WT.GFP ${ }^{+}$grafts formed complex ductal trees with alveoli (Fig. 3c, e). Only 1 out of $5 A F-1^{0}$.GFP $P^{+}$grafts showed some ductal growth with $15 \%$ fat pad filling; alveoli were absent (Fig. 3d, e). When the $W T$ grafts developed normally (Fig. $3 \mathrm{f}, \mathrm{h}, \mathrm{j}$ ), the contralateral $A F-2^{0} . G F P^{+}$grafts grew neither in nulliparous nor pregnant hosts (Fig. 3g, i, j). Thus, both AF-1 and AF-2 are required in MECs for ductal outgrowth ${ }^{19,20}$, side branching, and alveologenesis. AF-1 abrogation is compatible with limited ductal elongation during pregnancy, whereas $A F-2^{0}$ MECs fully recapitulate the $E R \alpha^{-/-}$MEC phenotype with a complete developmental block ${ }^{16}$.
Steroid hormones induce mammary gland development largely through paracrine signalling ${ }^{2}$. Areg is an essential mediator of E2induced cell proliferation during puberty ${ }^{19}$ and Wnt4 an important activator of stem cells, which can be induced by E2 in pubertal mammary glands ${ }^{21}$. In mammary glands from pubertal age $A F-1^{0}$ and $A F-2^{0}$ mice, Areg and Wnt4 transcript levels were as low as in their $E R \alpha^{-/-}$counterparts, i.e., $<1$ or $10 \%$, respectively, as compared to $W T$ (Fig. 3k). Thus, transcription of Areg and Wnt 4 requires both $\mathrm{ER} \alpha \mathrm{AF}-1$ and AF-2, providing a mechanism for the growth defect in the mutant epithelia. Transcript levels of other ERa targets, $\mathrm{Pgrl}^{22}$ and $\mathrm{Prlr}^{23}$, were similarly decreased (Fig. 3k). However, specifically Pgrl levels were higher in $A F-1^{0}$ than in $A F-2^{0}$ and $E R \alpha^{-}-$mammary glands (Fig. 3k). The PgR protein was readily detected by IHC in luminal cells of $W T$ and $A F-1^{0}$, but not of $A F-2^{0}$ or $E R \alpha^{-1-}$ females (Fig. 3l) indicating that PgR expression is largely AF-2 dependent and somewhat AF-1 independent. 


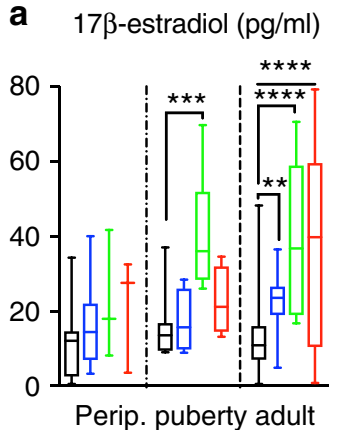

Androstenedione (ng/ml)

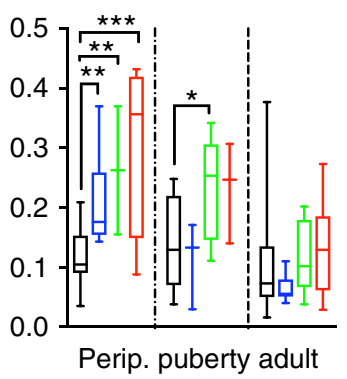

Testosterone (ng/ml)

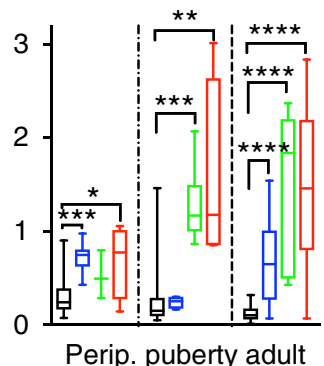

17-OH-progesterone ( $\mathrm{ng} / \mathrm{ml}$ )

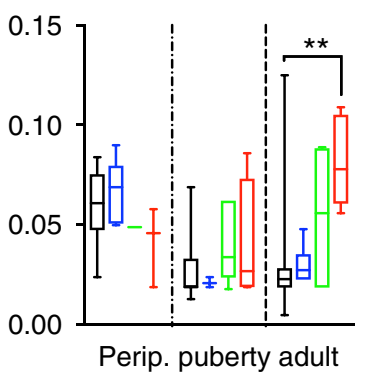

Progesterone (ng/ml)

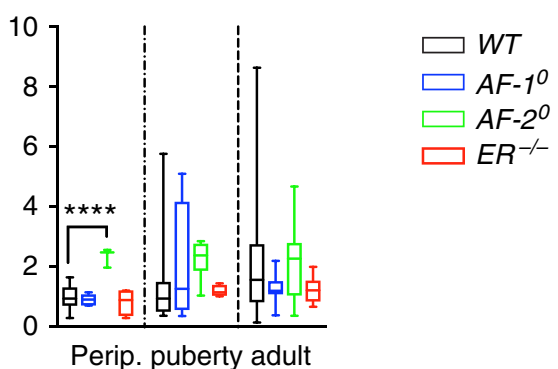

Corticosterone (ng/ml)

Deoxycorticosterone (ng/ml)

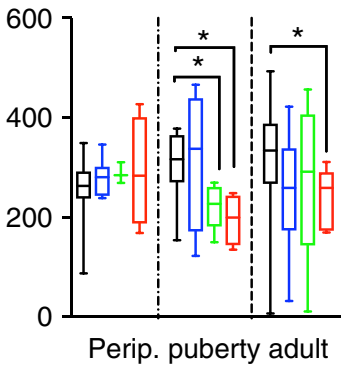

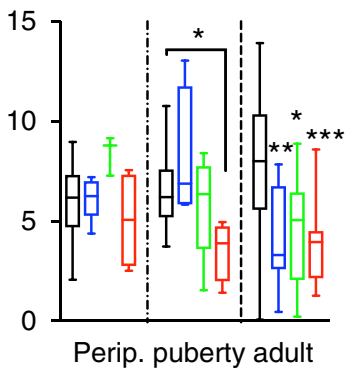

b

Cholesterol

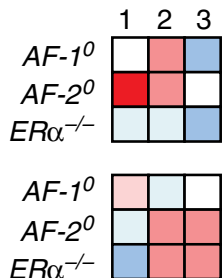

$\downarrow$

Pregnenole

$\downarrow$

Progesterone<smiles>C1CC1</smiles>

$17 \mathrm{OH}$-progesterone

$\downarrow$

\begin{tabular}{c|l|l|l|}
$A F-1^{\circ}$ & & & \\
$A F-2^{\circ}$ & & & \\
$E R \alpha^{-/}$ & & & \\
\hline
\end{tabular}

$A F-1^{0}$
$A F-2^{0}$
$E R \alpha^{-1-}$

$A F-1^{0}$

$A F-2^{O}$

$E R \alpha^{-/-}$

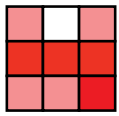

Androstenedione

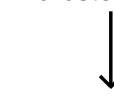

Testosterone

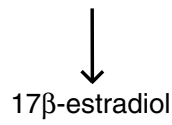

1: Peripuberty

2: Puberty

3: Adult

Fold change over WT littermate:

Fig. 2 Steroid hormone levels in $E R \alpha A F-1^{0}, E R \alpha A F-2^{0}$ and $E R \alpha^{-/-}$mice. a Box plots showing plasma levels of 17- $\beta$-estradiol, testosterone, progesterone, androstenedione, 17-OH-progesterone, corticosterone and deoxycorticosterone determined by LC/MS measured in peripubertal (3-week old), pubertal (4- to 7-week old) and adult (>8-week old) WT, AF- $7^{0}, A F-2^{0}$ and $E R \alpha^{-/-}$females $(n=3-25)$. Horizontal lines outside the boxes depict minimum and maximum values, upper and lower borders of the boxes represent lower and upper quartiles, and the line inside the box identifies the median. Unpaired, Mann-Whitney test. $\mathbf{b}$ Mean serum levels of the different steroids (shown in a) were plotted relative to average levels in WT littermates in the context of major biosynthetic pathways. Colour code represents fold changes over levels in the WT littermates

We hypothesised that the residual PgR expression in $A F-1^{0}$ epithelium may account for the partial outgrowth in this mutant observed in the older females and during pregnancy. To test whether prolonged PgR signalling is sufficient to stimulate ductal growth, we exposed mice bearing $A F-1^{0} . G F P^{+}$and WT.GFP epithelial grafts to pregnancy levels of progesterone by implanting slow-release pellets subcutaneously. Serum progesterone levels at sacrifice corresponded to those observed during pregnancy in control animals (Supplementary Figure 2a). While the contralateral WT.GFP ${ }^{+}$grafts showed increased side branching (Supplementary Figure 2b) confirming successful delivery of progesterone, the $A F-1^{0}$.GFP $P^{+}$epithelial grafts remained rudimentary (Supplementary Figure 2c) indicating that activation of $\mathrm{PgR}$ signalling is not sufficient to stimulate ductal elongation in $A F-1^{0}$ epithelial grafts. These observations support a model where the function of ER + sensor cells relies on both AF- 1 and AF-2 for the transcription of Areg and Wnt4 and potentially other factors and/or cell-intrinsic functions required for ductal elongation. 
a
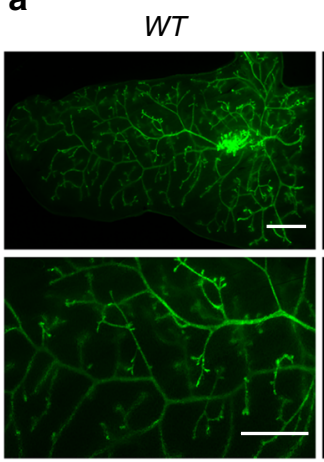

f
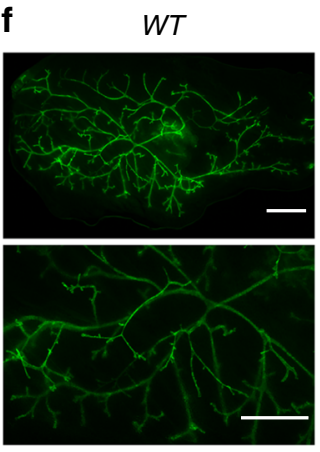
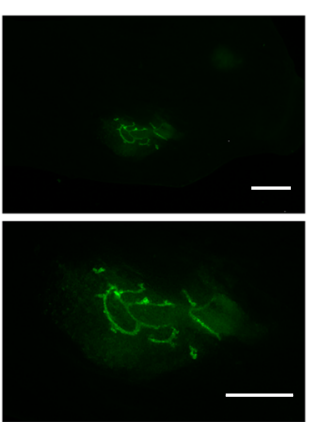

g $\quad A F-2^{\circ}$

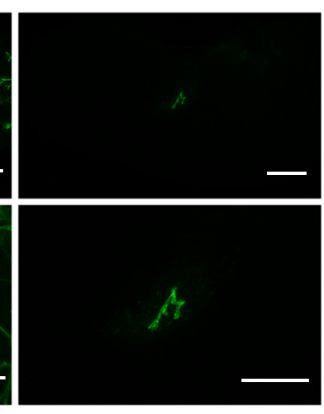

C
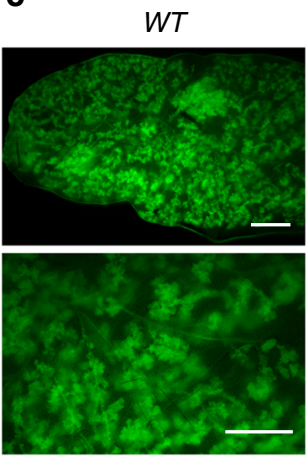

h

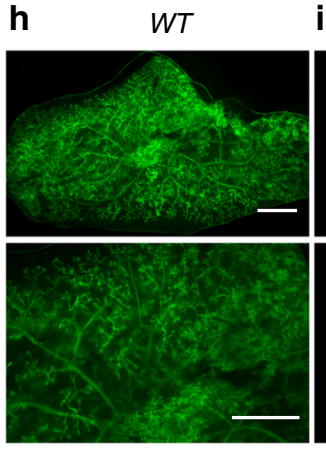

d

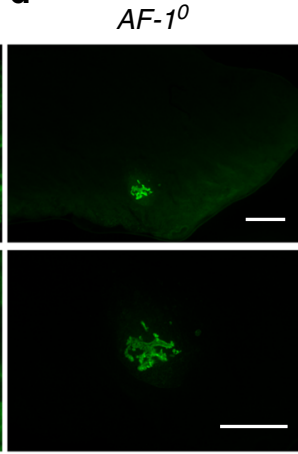

i

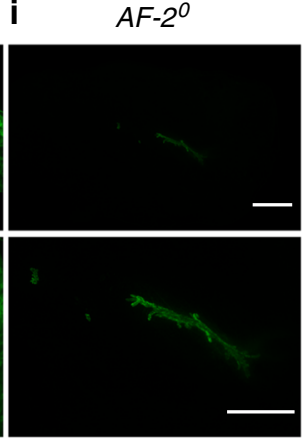

e

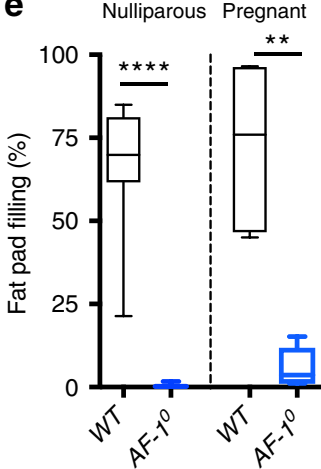

j

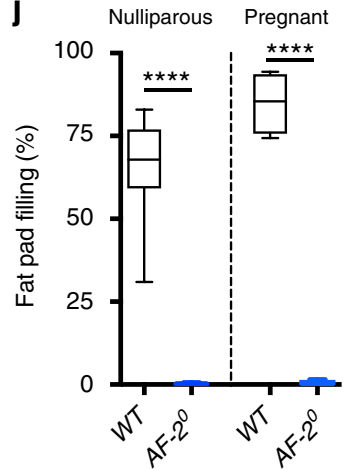

k

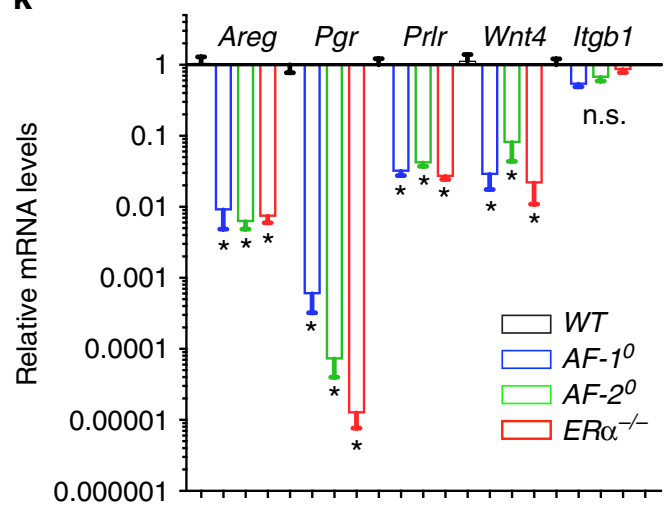

I

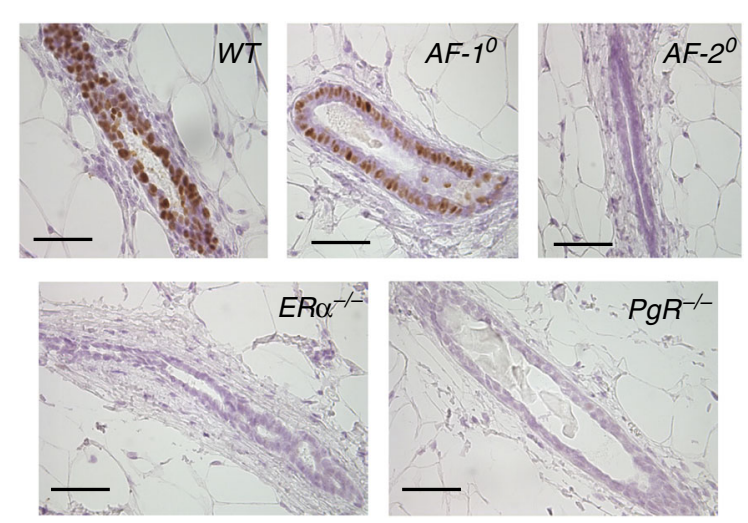

Fig. 3 Mammary epithelial-intrinsic role of the ER $\alpha$ AF-1 and AF-2 domains. a-d Fluorescence stereomicrographs of contralateral inguinal mammary fat pads engrafted with mammary epithelium from AF-10.GFP+ or WT.GFP+ littermates. Nulliparous (a, b) and day 16-18 pregnant (c, d) recipients are shown. Scale bars; $5 \mathrm{~mm}$ (top), $2 \mathrm{~mm}$ (bottom). e Box plot showing extent of fat pad filling by the engrafted epithelia in virgin $(n=18)$ and pregnant $(n=5)$ recipients. f-j Fluorescence stereomicroscopy of contralateral inguinal mammary fat pads engrafted with mammary epithelium from AF- $2^{0}$.GFP+ or WT.GFP+ littermates. Nulliparous (f, $\mathbf{g})$ and (P16-18) pregnant (h, i) recipients are shown. Scale bars; $5 \mathrm{~mm}$ (top) $2 \mathrm{~mm}$ (bottom). $\mathbf{j}$ Box plot showing extent of fat pad filling by the engrafted epithelia in virgin $(n=10)$ and pregnant $(n=4)$ recipients. For both box plots, horizontal lines outside the boxes depict minimum and maximum values, upper and lower borders of the box represent lower and upper quartiles and the line inside the box identifies the median. $\mathbf{k}$ Bar plot showing relative transcript levels of the ER $\alpha$ target genes Areg, Pgr1, Prlr and Wnt4, and a control gene, Itgb1, normalised to 36b4 and Hprt in mammary glands from peripubertal $W T, A F-1^{0}, A F-2^{0}$ and $E R \alpha^{-/-}$females. Data are shown as means \pm SEM of three independent experiments. Paired two-tailed Student's $t$ test, ${ }^{\star} p<0.05,{ }^{\star \star} p<0.01,{ }^{\star \star \star} p<0.001,{ }^{\star \star \star \star} p<0.0001$, n.s. not significant. I PgR IHC of mammary glands from 3-week-old WT, AF-10, and AF-20,$E R \alpha^{-/-}$and $P R^{-/-}$mice. Representative pictures of glands analysed from three females of each genotype are shown. Scale bar; $100 \mu \mathrm{m}$

The role of ERa in responder cells in ductal outgrowth. We previously reported that when $E R \alpha^{-/}-R O S A 26^{+}$MECs were mingled with excess WT MECs and this mixture was then grafted to cleared mammary fat pads, $E R \alpha^{-/-}$MECs contributed to the chimeric outgrowth ${ }^{16}$ and gave rise to the model of sensor and responder cells ${ }^{24,25}$. To compare the ability of $A F-1^{0}, A F-2^{0}$ and $E R \alpha^{-1-}$ MECs, none of which were able to grow out on their own, to contribute to mammary gland development in the context of excess WT MECs that release paracrine and potentially other signals, we co-injected either ER $\alpha W T . G F P^{+}$or ER $\alpha$ mutant.
GFP $^{+}$MECs mixed with WT.DsRed ${ }^{+}$MECs in a 1:10 ratio (Fig. 4a) into contralateral glands. The resulting $W T . G F P^{+}: W T$. $\mathrm{DsRed}^{+}$chimeric glands appeared to 4\% GFP+, almost 10 times as many seemed DsRed $+(37 \%)$, while $59 \%$ scored double positive by fluorescence stereomicroscopy (Fig. $4 \mathrm{~b}, \mathrm{c})$. In the $E R \alpha$ ${ }^{-1}$. GFP $^{+}:$WT.DsRed ${ }^{+}$chimeras, only $23 \%$ were double positive whereas $77 \%$ appeared DsRed+ (Fig. 4b, c). This indicates that $E R \alpha^{-/-} . G F P^{+}$MECs are able to proliferate when mixed with WT.DsRed ${ }^{+}$MECs, but are less efficient than ER $\alpha W T . G F P^{+}$ MECs in contributing to ductal outgrowth. This demonstrates 
a

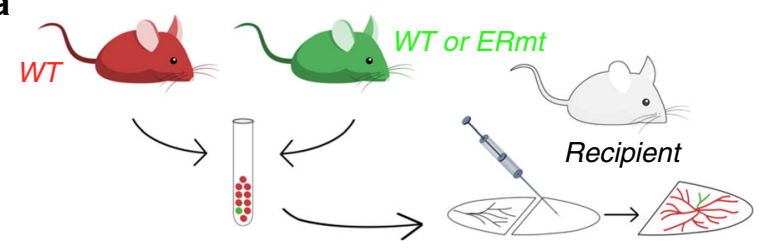

b
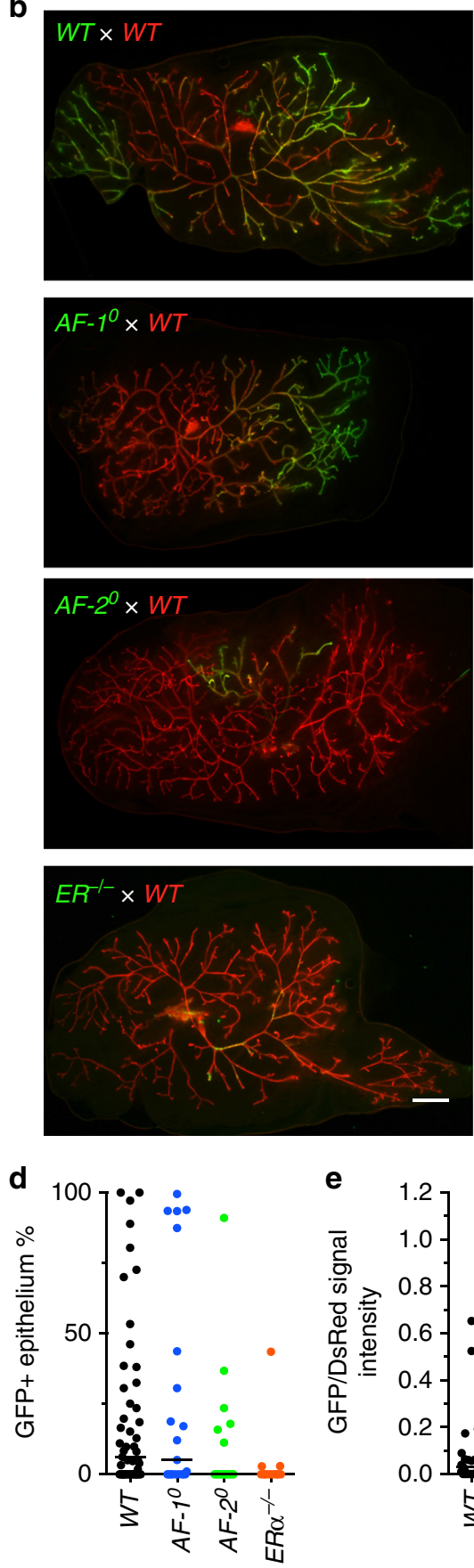
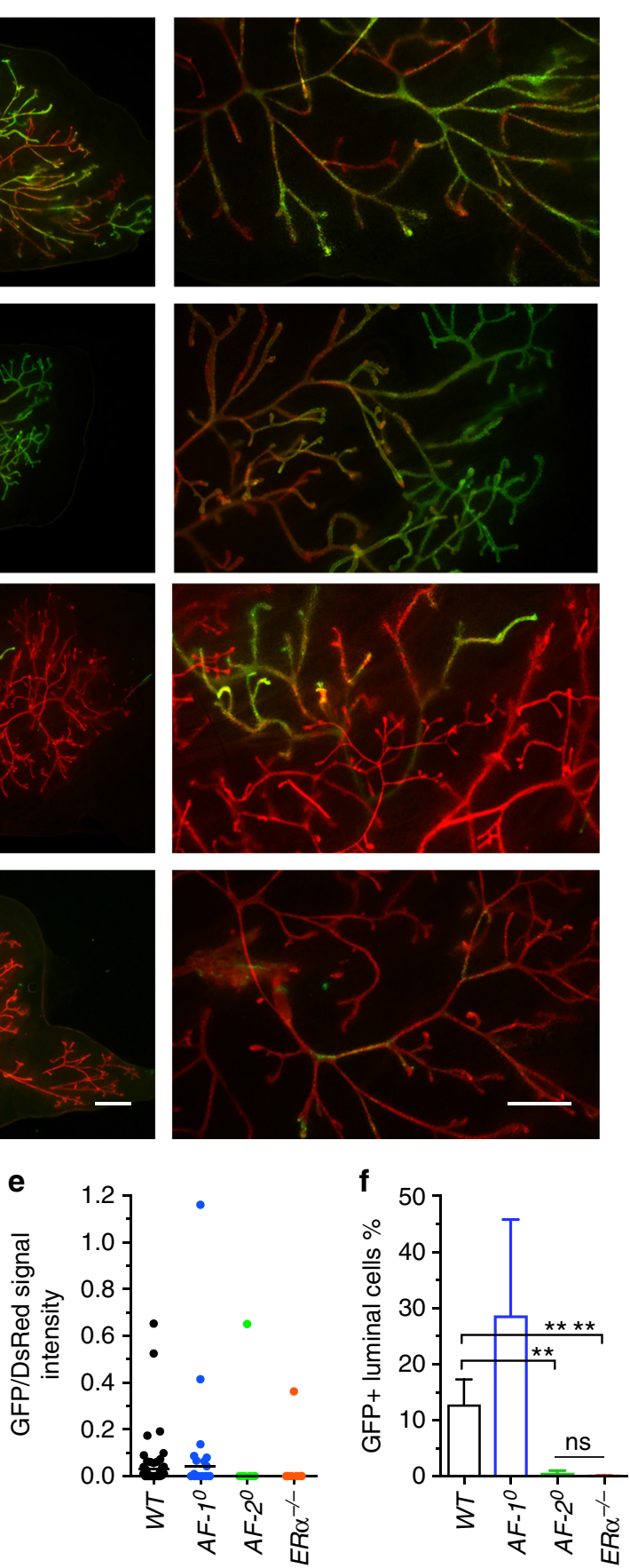
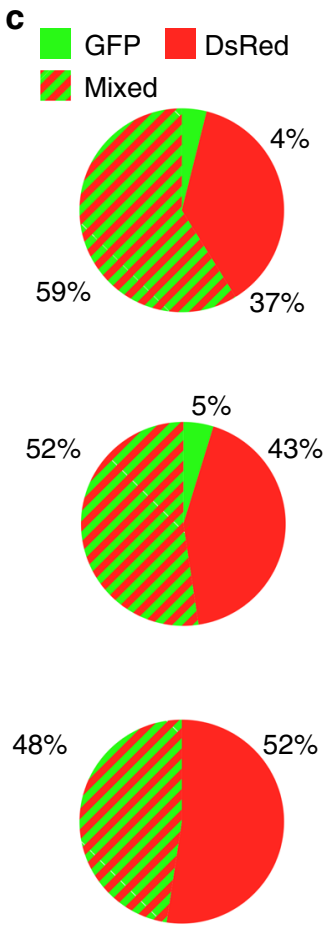

$23 \%$
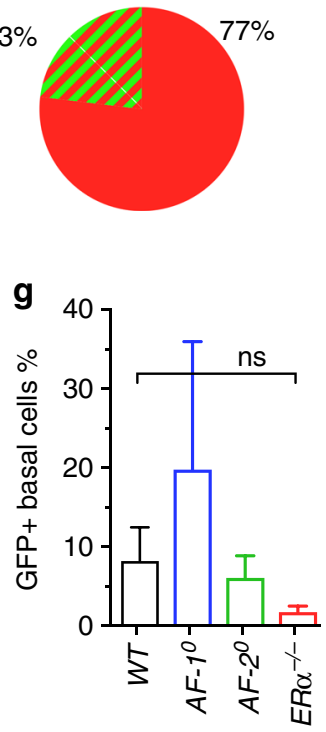

that ERa is required not only in the ERa + sensor cells but also in the apparently ER $\alpha$ - responder MECs.

To assess whether ER $\alpha$ function in responder cells requires AF1 and AF-2, we generated chimeras with $A F-1^{0}$ or $A F-2^{0}$ cells. $A F-$ $1^{0}$. GFP $^{+}: W T . D s R e d^{+}$chimeras were comparable to the WT chimeras (Fig. 4b, c). AF- $2^{0} \cdot G F P^{+}: W T . D s R e d^{+}$chimeras were more similar to $E R \alpha^{-/-}$.GFP ${ }^{+}$:WT.DsRed ${ }^{+}$chimeras with $52 \%$ appearing DsRed+ only and $48 \%$ double positive (Fig. $4 \mathrm{~b}, \mathrm{c}$ ). Thus, ER $\alpha$ function in the responder cells is AF-1 independent but AF-2 dependent.

We approximatively evaluated the GFP signal (Fig. 3d) and the ratio of GFP to RFP signal intensities (Fig. 4e) in chimeric epithelia by analysis of a 2D-image of the chimeric gland and showed that the data points were similarly distributed for $W T$ and 
Fig. 4 Contribution of $A F-1^{0}, A F-2^{0}$ and $E R \alpha^{-/-}$cells to chimeric ducts with WT MECs. a Scheme of experimental design. After cell dissociation, 10,000 $E R \alpha$ mutant (ERmt) or WT GFP+ epithelial cells were mixed with 90,000 WT.DsRed ${ }^{+}$epithelial cells and injected into the cleared mammary fat pad of peripubertal recipient mice. b Representative fluorescence stereomicrographs of chimeric epithelia from WT.GFP+ or ER $\alpha . m u t a n t . G F P^{+}$and WT.DsRed ${ }^{+}$ cells mixed in a 1:10 ratio. Hosts were analysed 10 weeks after engraftment. Scale bars; $1 \mathrm{~mm}$ (left) $0.2 \mathrm{~mm}$ (right). c Pie charts showing the proportion of engrafted mammary glands appearing exclusively DsRed ${ }^{+}$, exclusively GFP+, or mixed (red and green stripes) based on evaluation at low (7.8 $\times$) magnification of fluorescence stereomicrographs. From top to bottom, $n=51,21,17$ and 13 . $\mathbf{d}$ Dot plot showing the percentage of the reconstituted ductal epithelium that is GFP+ in virgin mice based on images at $7.8 \times$ magnification, $(n=13-51)$ bars indicate medians. e Dot plot showing the ratio of GFP/ DsRed signal intensity of the reconstituted ductal epithelia based on images at $7.8 \times$ magnification, bars indicate medians $(n=29,15,7$ and 7$)$. $\mathbf{f}, \mathbf{g}$ Bar graphs showing flow cytometric analysis of the percentage of GFP+ cells in the CD24 ${ }^{\text {high }}$ CD 49flow $\mathbf{f}$ and CD24low CD49fhigh $\mathbf{g}$ cell populations of reconstituted chimeric mammary epithelia. From left to right, $n=20,5,8$ and 6. Shown are means \pm SEM; Mann-Whitney test, two-tailed, ${ }^{\star \star \star} p<0.01,{ }^{\star \star \star \star \star} p$ $<0.0001$, n.s. not significant

$A F-1^{0}$ chimeras whereas they tended to be lower for $A F-2^{0}$ and $E R \alpha^{-/-}$chimeras (Fig. $4 \mathrm{~d}$, e). To determine the contribution of GFP + MECs quantitatively, we analysed chimeric glands by FACS. After lineage + cell depletion, we discriminated CD24 high $C D 49 f^{\text {low }}$ luminal and CD24 ${ }^{\text {low }}$ CD $49 f^{\text {high }}$ basal cells ${ }^{26}$. $W T . G F P^{+}$cells represented $12.9 \pm 3.5 \%$ of the luminal and $8.2 \pm 2.7 \%$ of the basal cell population (Fig. $4 \mathrm{f}, \mathrm{g}$ ) reflecting the original $10 \% \mathrm{GFP}^{+}$cells. The deviation from the predicted $10 \%$ may reflect biological variation or cell type-specific differences in expression from the chicken $\beta$-actin promoter driving $\mathrm{GFP}^{27,28}$. $A F-1^{0}$.GFP ${ }^{+}$MECs contributed similarly to both cell lineages. $A F-2^{0} . G F P^{+}$and $E R \alpha^{-/-} . G F P^{+}$cells were significantly less represented with $<1 \%$ of the luminal cells (Fig. 4 f) and $6 \%$ and $1.7 \%$, respectively, of the basal cells but the latter failed to reach statistical significance (Fig. $4 \mathrm{~g}$ ).

Thus, while both AF-1 and AF-2 are required for the expression of essential paracrine mediators in sensor cells, the responder cells require ER $\alpha$ but more specifically AF-2; AF-1 is not required in responder cells during ductal elongation.

The role of AF-1, AF-2 and ERa during pregnancy. During pregnancy, E2 levels increase from $<10$ to $100 \mathrm{pg} / \mathrm{ml}^{29}$ and there is extensive cell proliferation of MECs, which are hormone receptor negative by $\mathrm{IHC}^{30,31}$. Fluorescence stereomicroscopy at the end of pregnancy showed that $90 \%$ of $W T . G F P^{+}: W T . D s R e d^{+}$chimeras were mixed while $10 \%$ appeared DsRed + only (Fig. $5 \mathrm{a}, \mathrm{b}$ ). Of the $A F-1^{0}$.GFP ${ }^{+}: W T . D s R e d^{+}$and $A F-2^{0}$.GFP ${ }^{+}: W T . D s R e d^{+}$chimeras $43 \%$ scored double positive and $57 \%$ DsRed + only whereas of the $E R \alpha^{-l-} . G F P^{+}$chimeras $67 \%$ scored double positive (Fig. 5a, b). Approximate evaluation of the GFP signal (Fig. 5c) and the ratio of GFP to RFP signal intensity (Fig. $5 \mathrm{~d}$ ) based on a 2D image showed similar distributions among the chimeras. Comparison of the contribution of the different mutant cells to that of WT cells before and at the end of pregnancy indicates that loss of ERa function promotes cell expansion during pregnancy largely through AF-2, whereas AF-1 loss may have an inhibitory effect on cell expansion. Together, the observations on the chimeric outgrowths suggests that ERa function in the ERa low cells is biphasic with a growth-stimulatory role during puberty and an inhibitory role during pregnancy both of which appear AF-2 dependent and AF-1 independent.

Evaluating ERa in vivo function in by intraductal grafting. The surprising finding that $\mathrm{ER} \alpha$ signalling appeared to have a biphasic effect on MECs depending on the developmental stage incited us to look at ERa in vivo function by an alternative approach that bypasses the need of dissociated MECs to establish themselves in the mammary fat pad because this does not happen physiologically during development and could lead to artefacts, which may confound the interpretation of the results. Human breast epithelial cells have difficulties in establishing themselves in the mouse mammary fat pad but when injected into the milk ducts they insert into the mouse mammary epithelium and proliferate there $^{32}$. We ascertained that the same holds true for murine MECs by injecting WT.DsRed ${ }^{+}$MECs intraductally into NOD scid gamma (NSG).GFP ${ }^{+}$females. Five days later, WT.DsRed ${ }^{+}$ MECs were detected in the $\mathrm{GFP}^{+}$ducts by fluorescence stereomicroscopy (Fig. 6a). Double immunofluorescence revealed that most DsRed + cells were luminal MECs, distinct from the P63+ basal cells (Fig. 6b); about $10 \%$ of the DsRed + cells gave rise to myoepithelial cells as identified by smooth muscle actin costaining (Fig. 6c).

Next, we injected MECs from WT.GFP ${ }^{+}$and $E R \alpha^{-/-} . G F P^{+}$ littermates into contralateral glands and analysed them 5 days later by stereomicroscopy. The fluorescent signal from $E R \alpha^{-/-}$. $\mathrm{GFP}^{+}$cells was consistently lower than the signal from the contralateral WT.GFP ${ }^{+}$cells (Fig. 6d, f). When hosts were mated and their engrafted glands were analysed in late pregnancy, the signals became comparable (Fig. 6e, f) suggesting that $E R \alpha^{-/-}$ MECs caught up with their WT counterparts as observed in the context of the chimeric epithelial outgrowths above (Fig. 5a). Quantification of GFP + cells by FACS revealed that WT.GFP ${ }^{+}$ cells represented $4.4 \%$ and $E R \alpha^{-/-} . G F P^{+}$cells $<0.7 \%$ of the dissociated cells in virgin mice whereas at day $14.5-16.5$ of pregnancy, the contributions of WT.GFP ${ }^{+}$and $E R \alpha^{-/-} . G F P^{+}$ MECs were comparable (Fig. 6g, h).

Having ascertained that the biphasic effect of ERa observed in the context of chimeric outgrowths is reproduced in the intraductal model, we evaluated the role of AF-1 and AF-2. Because of the inter-experimental variability in the cell preparations, we normalised the individual ER $\alpha$ mutant cell numbers to the contralateral WT cells. In the nulliparous hosts, all three ER $\alpha$ mutants established themselves less well intraductally than their WT counterparts; $A F-1^{0}$ MECs showed $35 \%, A F-2^{0}$ MECs $83 \%$, and $E R \alpha^{-1-}$ MECs $70 \%$ reduction, respectively (Fig. 6i). Towards the end of pregnancy, none of the mutants differed significantly from the WT controls (Fig. 6j). Thus, by two distinct experimental approaches a biphasic effect of $E R \alpha^{-/}$through $A F-2^{0}$ in MECs is revealed. AF- 1 function which was not required for ductal elongation in the context of chimeric glands did affect the ability of MECs to establish themselves intraductally arguing that it may affect cell-cell interactions required for the insertion.

The finding that as early as 5 days after cell injection the number of $W T . G F P^{+}$MECs that have inserted into the ducts exceeds that of $A F-2^{0}$ and $E R \alpha^{-/}$MECs by several fold, suggested that MECs require ER $\alpha$ to adhere and insert themselves into the host epithelium.

To assess the proliferative indices of $E R \alpha^{-/-}$MECs and WT MECs during puberty and pregnancy we took different approaches. In one setting, we measured cell proliferation of $\mathrm{ER}^{-1-}$.GFP ${ }^{+}$.WT.DsRed ${ }^{+}$and WT.GFP ${ }^{+}$.WT.DsRed ${ }^{+}$chimeras during ductal elongation by Ki67 staining because the number of $E R \alpha^{-1-}$ MECs obtained after intraductal injection is very low in virgin recipients. In the other setting, we injected EdU into pregnant mice, which had been intraductally engrafted with ERa 
a
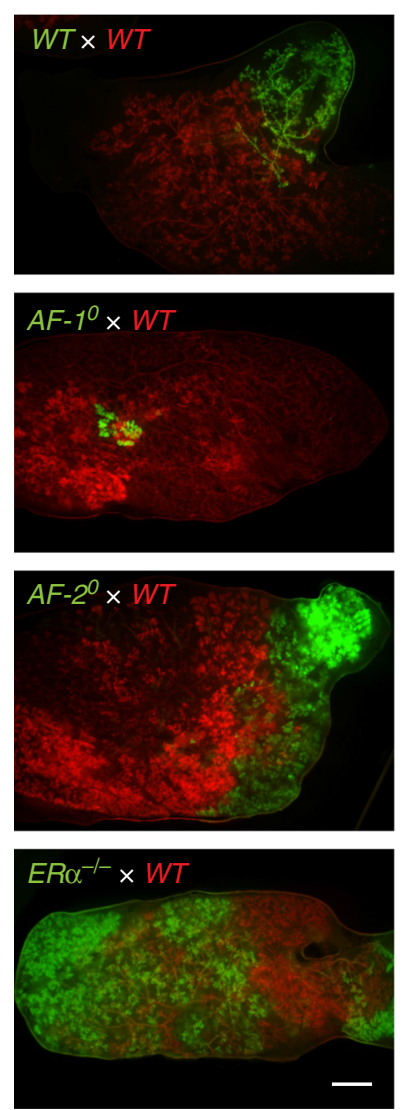
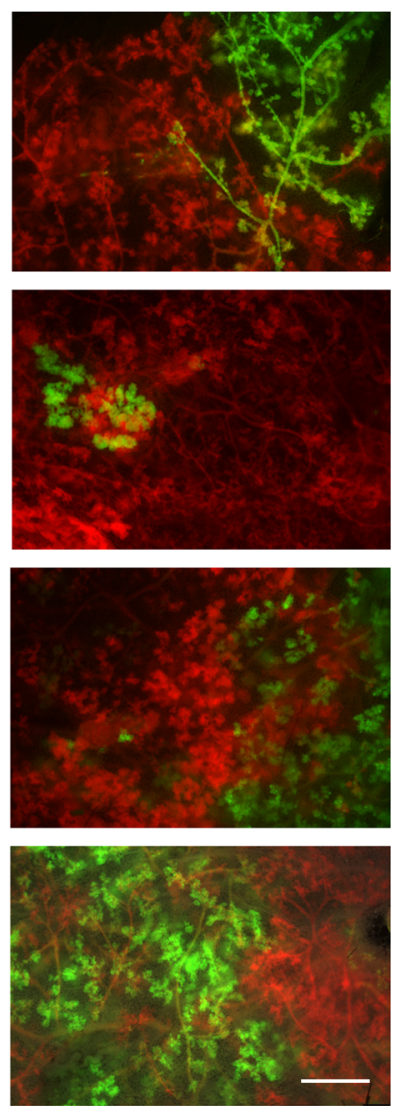

b

DsRed 2 Mixed
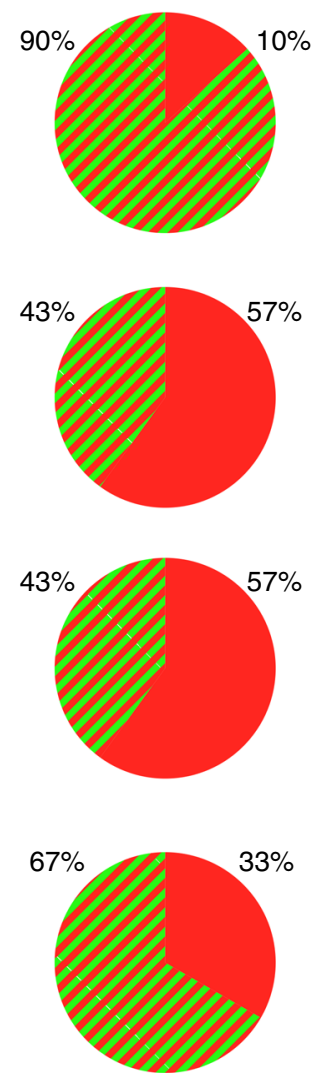

C

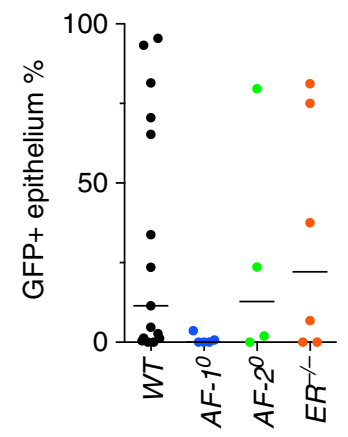

d

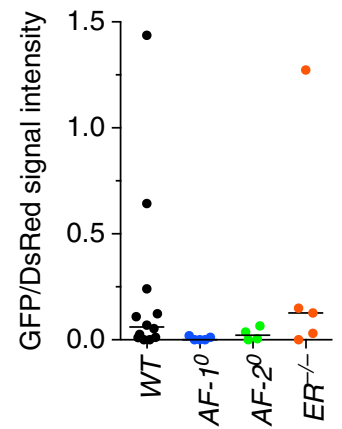

Fig. 5 Proliferation of $A F-1^{0}, A F-2^{0}$ and $E R \alpha^{-/-}$cells in chimeric epithelia during pregnancy. a Representative fluorescence stereomicrographs of chimeric epithelia from WT.GFP+ or ER $\alpha$ mutant.GFP ${ }^{+}$and WT.DsRed ${ }^{+}$cells mixed in a 1:10 ratio. Hosts were analysed at P16-18. Scale bars; $1 \mathrm{~mm}$. b Pie charts showing the number of mammary glands presenting only DsRed ${ }^{+}$epithelial regenerations (red) or mixed ${ }^{+}$and GFP ${ }^{+}$regenerations (red and green stripes) based on evaluation on "low magnification $7.8 \times$ " fluorescence stereomicrographs; from top to bottom, $n=20,7,7$ and 6 . c Dot plot showing percentage of area filled with GFP ${ }^{+}$structures over total area filled in chimeric glands during pregnancy; evaluation at $7.8 \times$ magnification; shown are means \pm SEM. $\mathbf{d}$ Dot plot showing ratios of GFP over DsRed signal intensity of different chimeras in pregnant hosts $(n=4-16$; black line: median)

-/-.GFP or $A F-2^{0}$.GFP MECs contralateral of WT.GFP MECs and subsequently quantified the GFP and EdU double positive cells. In both scenarios the proliferative indices were comparable between $W T$ and ER mutant MECs (Fig. 6k, l). Thus, the absence of ER does not impair cell-intrinsic proliferation.

We hypothesised that the results may related to different numbers of stem/progenitor cells present in the mutant mammary epithelia. However, because of the low number of MECs that can be isolated from the ER $\alpha$ mutant mammary glands it was not practical to FACS purify any particular subpopulations for in vivo experiments. To assess whether the luminal and basal progenitor cell populations are affected by different $E R \alpha$ mutations, we FACS profiled mammary gland cells after lineage ${ }^{+}$cell depletion with CD24 and CD49f $\mathrm{f}^{26,33}$. While the $W T$ profiles were consistent between independent experiments, the $A F-1^{0}, A F-2^{0}$ and $E R \alpha^{-/-}$MECs showed major shifts in both CD24 and CD49f expression, making it impossible to identify the different progenitor populations (Fig. $6 \mathrm{~m}$ ).

ERa-dependent gene expression in mammary epithelial cells. To discern the molecular basis of the $E R \alpha^{-1-}$ MEC phenotypes, and to further test for evidence that stem cell function is impaired by abrogating ER $\alpha$ signalling, WT.GFP ${ }^{+}$and $E R \alpha^{-/-}$.GFP ${ }^{+}$ MECs were intraductally injected to contralateral glands, isolated from pregnant hosts by FACS sorting for GFP, and analysed by RNA sequencing. Principal component analysis separated samples by $E R \alpha$ genotype (Fig. 7a). A total of 651 genes were differentially expressed, most of which were lower in the $E R \alpha^{-/-}$. $\mathrm{GFP}^{+}$MECs (>twofold, FDR < 0.05) (Fig. 7b).

Expression levels of genes that mark ERa high $\mathrm{MECs}^{34}$, including Esr1 itself, were low and no significant differences were found consistent with the scarcity of ERa+ MECs in the pregnant mammary epithelium (Fig. 7c). Milk protein coding genes, were highly expressed in both $W T$ and $E R \alpha^{-/-}$MECs (Fig. 7d) establishing that ERa is not required for functional differentiation, at least not cell intrinsically. MetaCore terms related to cytoskeleton and cell adhesion were decreased in the $E R \alpha^{-/-}$MECs (Fig. 7e) providing potential molecular underpinnings for impaired intraepithelial insertion. MetaCore terms related to immune signalling were increased in $E R \alpha^{-/-}$MECs (Fig. 7f). Reactome ${ }^{35}$ analysis revealed decreased keratinisation (Fig. 8a) and confirmed increased expression of immunity-related genes in $E R \alpha^{-1-}$ MECs (Fig. $7 \mathrm{~g}$ ). Moreover, Ephrin and FGFR signalling as well as ECM remodelling were decreased (Fig. 7h); all three have been implicated in pubertal growth ${ }^{36,37}$ but had not previously been linked to ERa signalling directly. GO terms and KEGG terms highlighted that the upregulated genes relate to $\mathrm{T}$ cell immunity (Fig. 7i-j).

We noticed basal markers like Krt5, Snai2, P63 and Frizzled7 among the most differentially expressed genes (Fig. 8a). Gene set enrichment analysis for hallmark gene sets ${ }^{38}$ showed that an EMT signature was most similar with $p=10 \mathrm{E} 28$ and compared to 


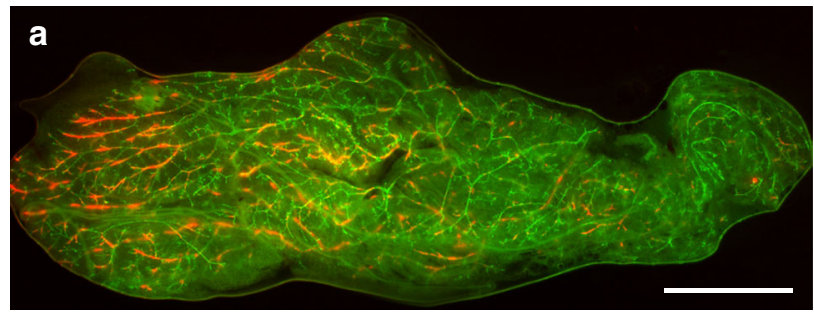

b

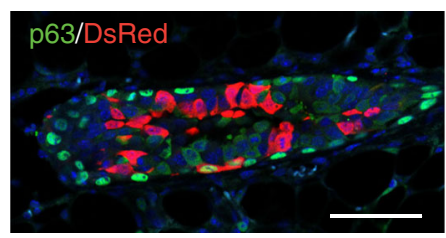

c

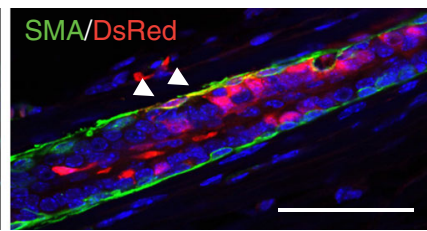

f

Nullip. preg.

g

Nullip.

h

Preg.
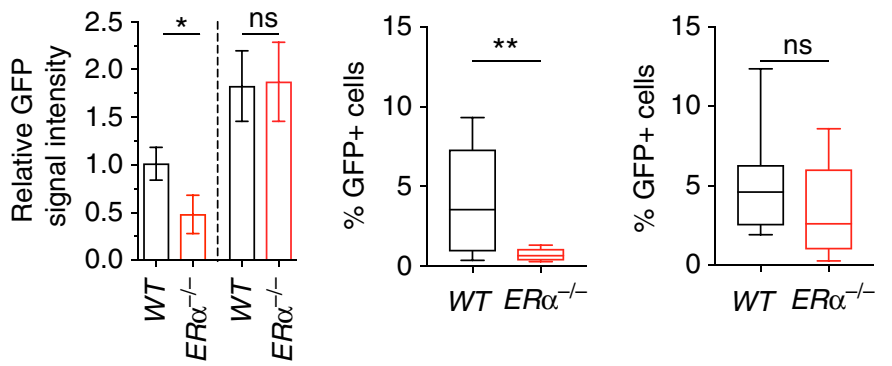

i

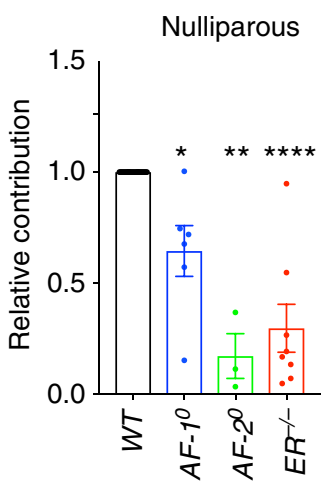

k

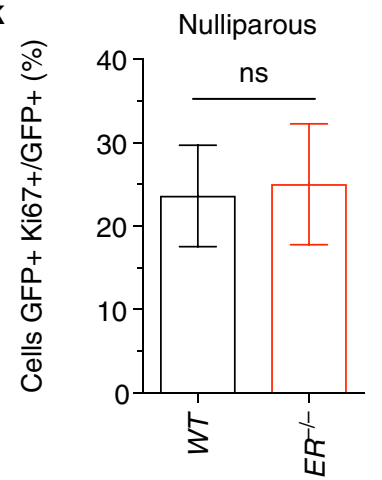

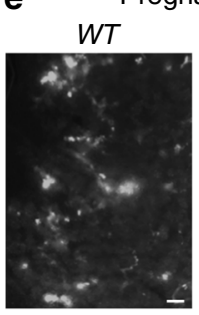

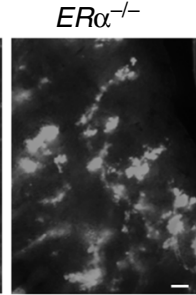

j

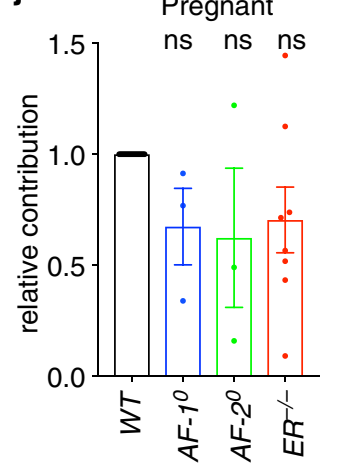

I

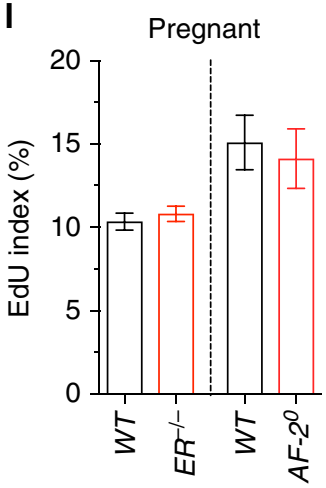

m
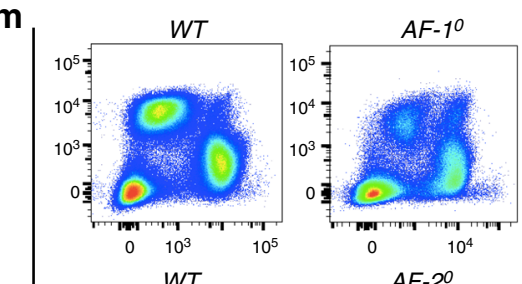

ปั่

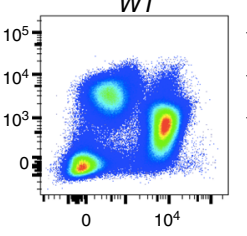

WT

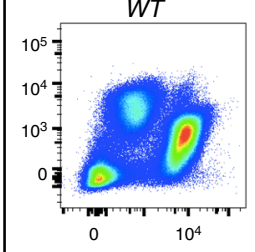

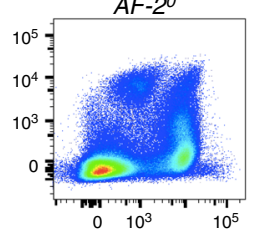

$E R^{-/-}$

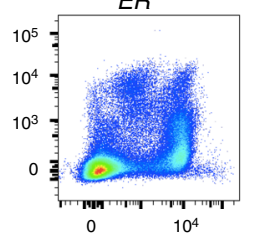

CD49f

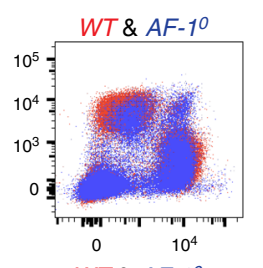

$W T \& A F-2^{0}$
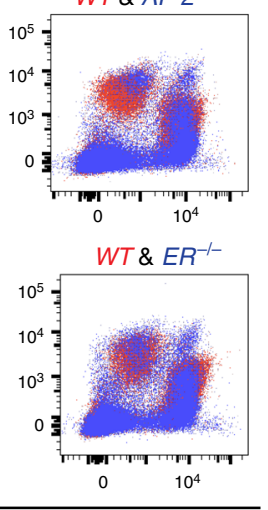

$0^{4}$

Fig. 6 Intraductal engraftment of WT and ER $\alpha^{-/-}$MECs. a Fluorescence stereomicrograph of NSG.GFP+ mammary gland 5 days after intraductal injection of WT.DsRed ${ }^{+}$MECs, representative of nine successfully injected glands. Scale bar; $1 \mathrm{~mm}$. b, c Double immunofluorescence with anti-P63 and anti-RFP antibodies $\mathbf{b}$ or anti- $\alpha$ Sma and anti-RFP antibodies c counterstained with DAPI. Scale bars; $50 \mu \mathrm{m}$. Representative pictures of injected glands from three females. d, e Fluorescence stereomicrographs of contralateral mammary glands 5 days after intraductal injection with WT.GFP+ or $E R \alpha^{-1-}$.GFP+ in nulliparous d or day 16-18 pregnant host (e). Scale bars; $500 \mu \mathrm{m}$. f Bar plot showing relative GFP signal intensity in contralateral glands injected with WT. $\mathrm{GFP}^{+}$or ER $\alpha^{-/-}$.GFP+ cells in nulliparous and pregnant recipients, $(n=3-6$; mean \pm SEM). $\mathbf{g}$, $\mathbf{h}$ Box plots showing percentage of GFP + cells by FACS in nulliparous $\mathbf{g}$ and pregnant $\mathbf{h}$ hosts $(n=8,9)$. Whiskers depict minimum and maximum values, box borders lower and upper quartiles, line inside identifies the median. Student's paired $t$ test, two-tailed. $\mathbf{i}$, $\mathbf{j}$ Bar plots overlying dot plots showing relative contribution of GFP+ cells by FACS of intraductally engrafted glands from nulliparous (i) and pregnant (j) hosts, mean \pm SEM. $\mathbf{k}$ Box plot showing percentage of GFP and Ki67 double + over total GFP + cells from contralateral WT.GFP ${ }^{+}$or ER $\alpha$ mutant.GFP ${ }^{+}$with WT.DsRed ${ }^{+}$MECs chimeras in nulliparous recipients 4 weeks after engraftment $(n=3$; mean \pm SD). I Box plot showing the percentage of GFP and EdU double + over total GFP+ cells from contralateral inguinal mammary glands intraductally engrafted with WT.GFP+ or ER $\alpha^{-/-}$.GFP+ (left panel) and WT.GFP+ or AF-20.GFP+ MECs (right panel) in pregnant recipients P12.5 $(n=3 ;$ mean \pm SD). $\mathbf{m}$ Representative FACS plots showing CD49f and CD24 expression in Lin ${ }^{-}$cells from mammary glands of AF- $7^{0}, A F-2^{0}, E R \alpha^{-/-}$females and WT littermates. For both box plots, whiskers depict minimum and maximum values, borders of the box represent lower and upper quartiles, and line inside the box identifies the median. Paired two-tailed Student's $t$ test, ${ }^{\star} p<0.05,{ }^{\star \star} p<0.01,{ }^{\star \star \star} p<0.001,{ }^{\star \star \star \star} p<0.0001$, n.s. not significant 
a

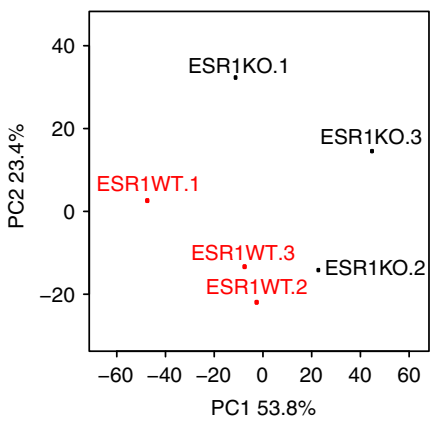

d

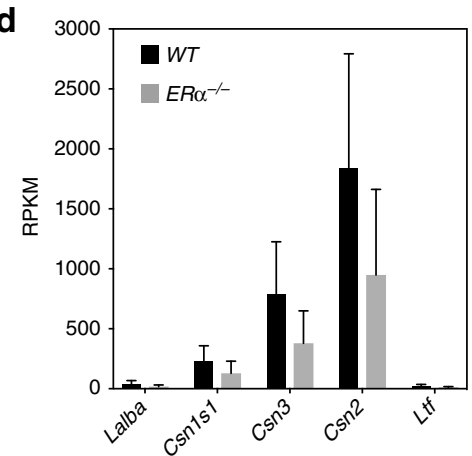

g

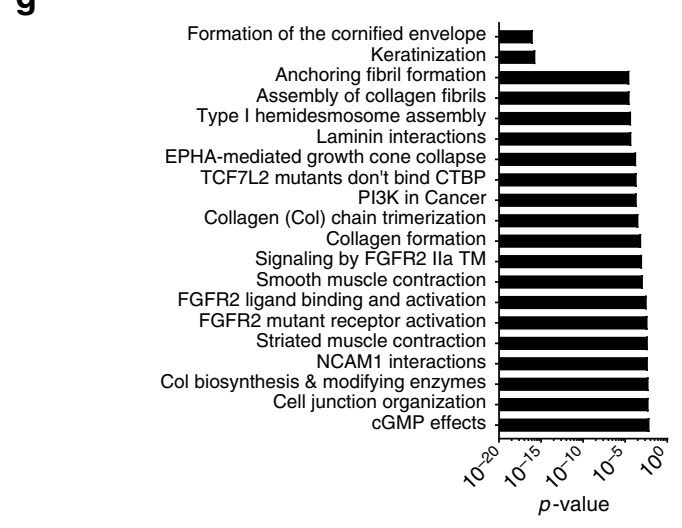

i

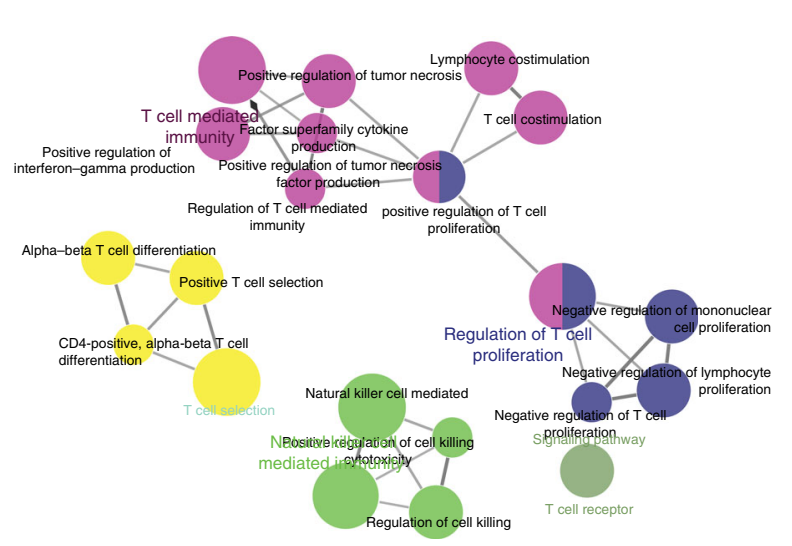

i b

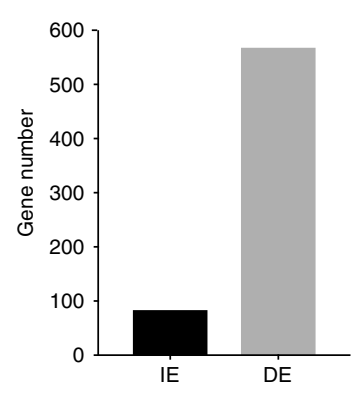

e

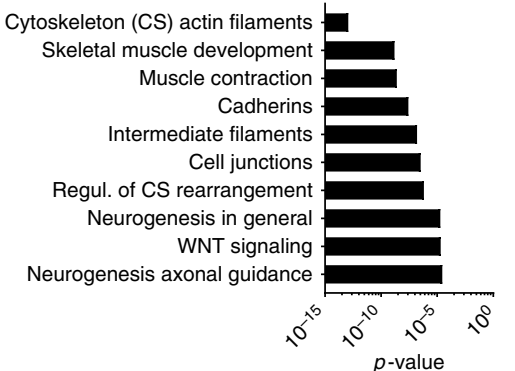

c

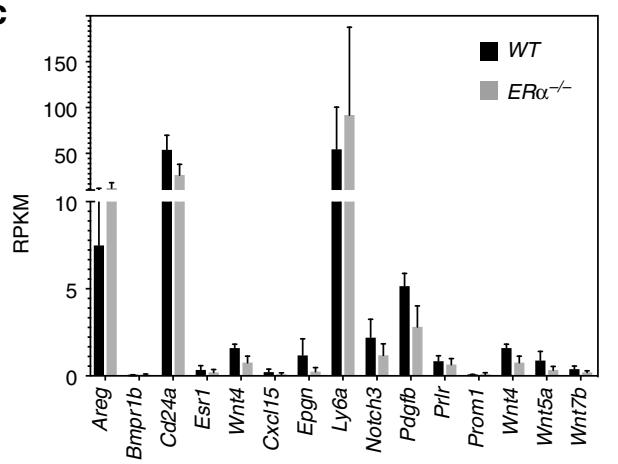

$\mathbf{f}$ $\mathbf{h}$
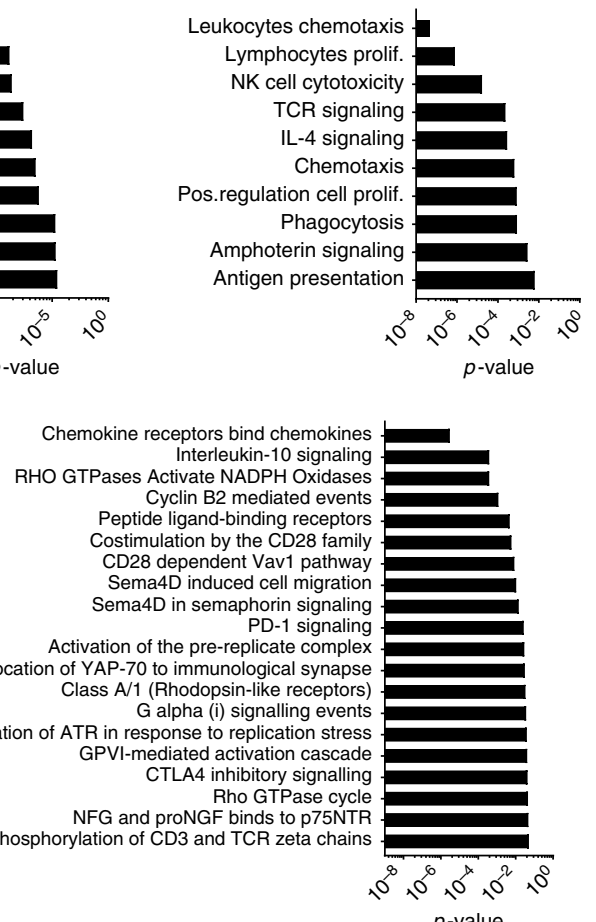

j

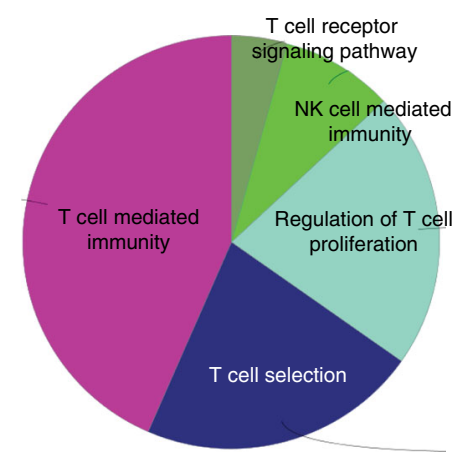

curated gene sets a mammary stem cell signature scored highest with $p=8 \mathrm{E} 105$ (Fig. 8b, c). Thus, ER $\alpha$ expression is not required for milk gene expression but is important for the transcriptional control of mammary stem/progenitor cell function as well as cellular interactions.
ERa status of luminal epithelial cells. Our finding that ERa has an important role in cells that appear ERa negative by IHC begged the question whether IHC may fail to detect functionally relevant ERa protein expression. Hence, we sought to detect $E R \alpha$ transcripts in situ in sections adjacent to sections assessed by IF 
Fig. 7 Global gene expression profile of $E R \alpha^{-/-}$and WT MECs. a Principal component (PC) analysis of RNAseq data showing the importance of the Esr1 genotype for global gene expression. b Bar graph showing the number of genes whose expression increased (IE) or decreased (DE) in ER $\alpha^{-/-}$.GFP+ vs. WT.GFP+ MECs engrafted intraductally to contralateral glands of NSG females and subsequently isolated by FACS-sorting from hosts during pregnancy. c Bar plot showing reads per kilobase million (RPKM) of ER $\alpha$ high, sensor cell markers expressed in ER $\alpha^{-/-}$.GFP+ and WT.GFP+ MECs that were engrafted intraductally to contralateral glands of NSG hosts and subsequently isolated by FACS-sorting from pregnant hosts. d Bar plot showing RPKM of milk genes expressed in FACS-sorted $E R \alpha^{-/-}$.GFP ${ }^{+}$and WT.GFP+ MECs grafted intraductally and isolated from pregnant hosts. e, $\mathbf{f}$ MetaCore analysis of genes showing decreased (e) or increased (f) expression, in ER $\alpha^{-/-}$.GFP+ MECs compared to WT.GFP+ MECs. The most significantly enriched terms are listed

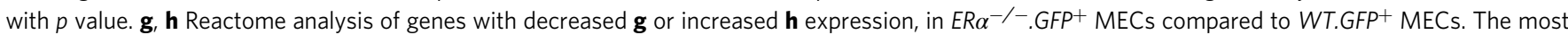
significantly enriched terms are listed with $p$ value. i Visual representation of GO terms with increased expression in ER $\alpha^{-/-}$.GFP+ vs. WT.GFP+ MECs by Cytoscape. $\mathbf{j}$ Pie chart showing proportions of KEGG terms among the genes with increased expression in the ERo ${ }^{-/-}$.GFP+ vs. WT.GFP+ MECs

a

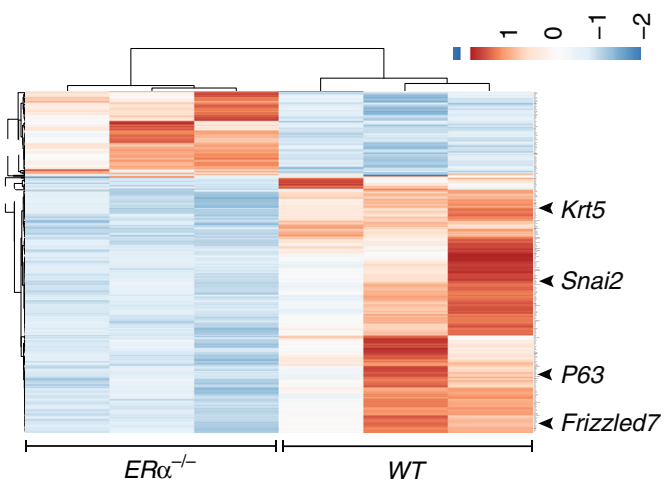

b

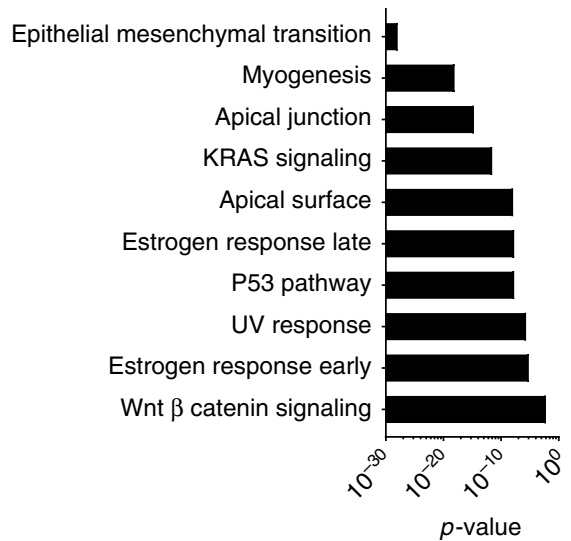

C

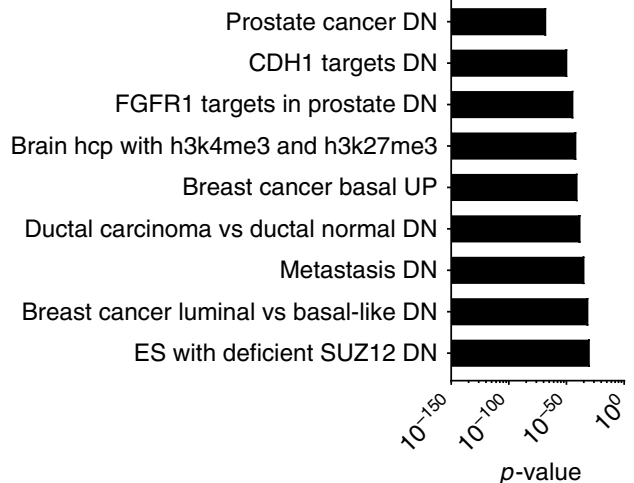

Fig. 8 ER $\alpha$-mediated control of gene expression signatures. a Heatmap of RNAseq transcriptomic analysis of WT.GFP+ and $E R \alpha^{-/-}$.GFP+ MECs that grew intraductally in NSG females contralateral glands. Row $Z$ scores of genes that were differentially expressed are included. $\mathbf{b}, \mathbf{c}$ Gene set enrichment analysis of genes that were down-regulated, in in $E R \alpha^{-/-}$.GFP+ MECs compared to WT.GFP+ control cells. By hallmark gene sets (b) and curated gene sets (c). The most significantly enriched terms with $p$ values are listed

for $\mathrm{ERa}$ protein expression. While ERa protein was detected in $50 \%$ of the luminal cells (Fig. 9a, c), RNAscope detected ER $\alpha$ mRNA in $80 \%$ of the luminal cells (Fig. 9b, c) indicating transcript expression in luminal cells other than the $50 \% \mathrm{ERa}+$ by IHC, the protein may be expressed at levels below the IHC detection limit possibly because of rapid turnover. Semiquantitative scoring based on the number of dots per cells showed approximately $20 \%$ of the luminal cells falling into the negative, the low (1) and medium (2) categories and $40 \%$ into the high ( $\geq 3$ ) (Fig. 9d), Of note, transcripts of the ERa target Areg were only detected in a subset of $15-30 \%$ of luminal cells (Fig. 9e), which we assume to be ERa ${ }^{\text {high }}$ sensor cells because they co-express PgR protein, here used as a proxy for ERa since the antibodies for ER do not work with RNAscope (Fig. 9e-g).

Thus, with respect to ERa status, at least three different luminal cell types can be distinguished. The sensor cells, ERa+ by IHC, the responder cells, which are ERa- by IHC yet express detectable amounts of ERa transcript, and ERa negative responder cells. Sensor cells require both AF-1 and AF-2 whereas the ERalow responder cells are AF-2-dependent. These three groups may represent three distinct classes of luminal epithelial cells or different zones of a gradient of different ERa expression levels.

\section{Discussion}

The present study of the in vivo role of ERa and its subdomains AF-1 and AF-2 in the mammary epithelium reveals unexpected complexities of this signalling pathway. Contrary to current thinking that there is a dichotomy between ERa+ and ERaluminal cells, we show that based on ER expression levels, a third luminal cell population, the ERalow cells, can be distinguished. These cells have readily detectable Esr1 transcripts but are characterised by low-level ERa protein expression, possibly attributable to high protein turnover. The percentage of luminal cells 

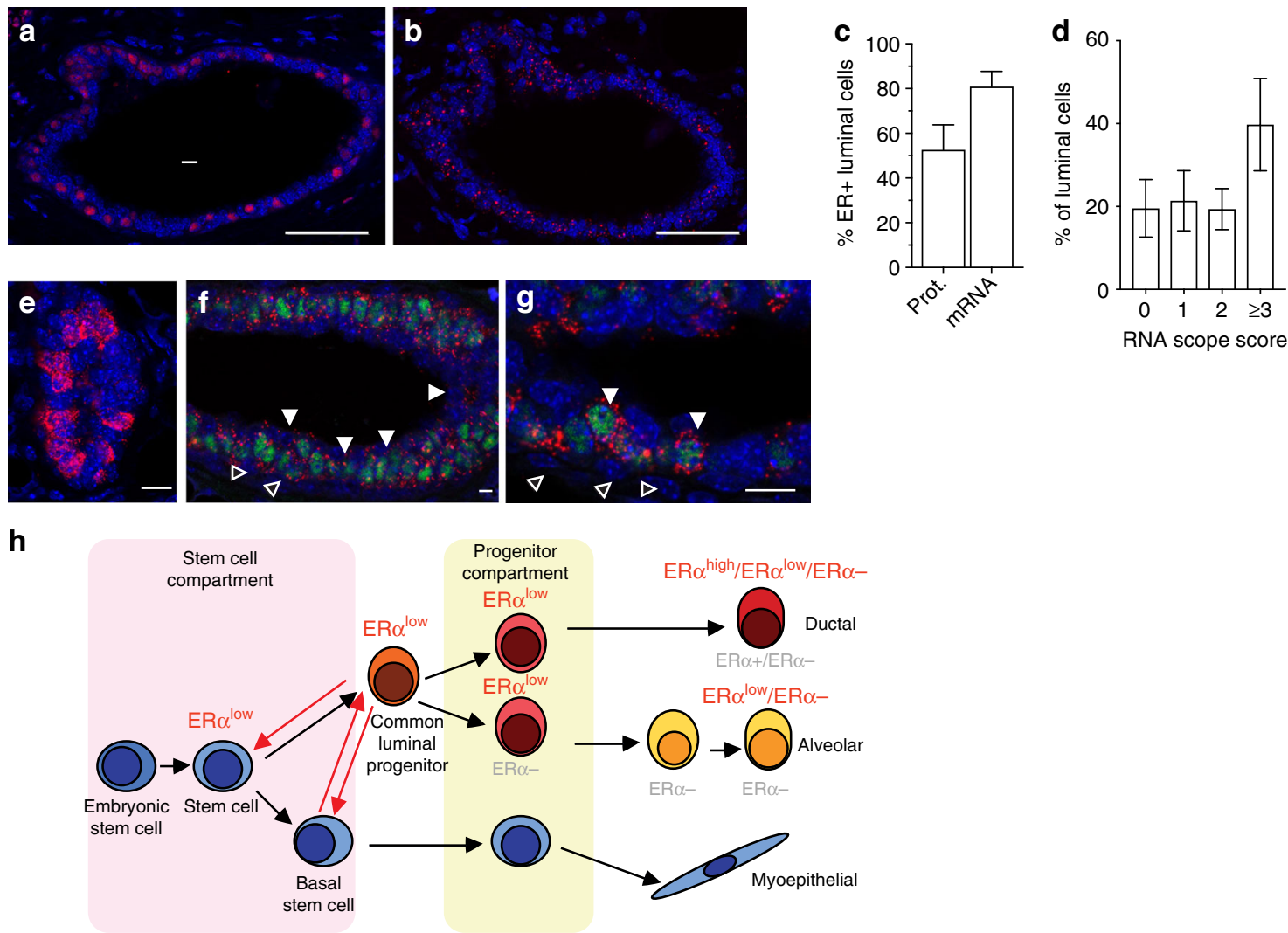

Fig. $9 E R \alpha$ mRNA and protein expression $E R \alpha^{-/-}$and WT MECs. a ER $\alpha$ immunofluorescence (red) and b RNAscope with anti-Esr1 probes (red) on an adjacent section counterstained with DAPI (blue) on mammary gland from 6-week-old WT female. Scale bars; 50 Hm. c Bar plot showing percentage of luminal cells with detectable levels of ER $\alpha$ protein and Esr1 mRNA at puberty $(n=5$; mean \pm SD). d Bar plot showing percentage of luminal cells with different Esr1 RNAscope scores ( $n=5$; mean \pm SD). e RNAscope with anti-Areg probes (red) counterstained with DAPI (blue) on mammary gland from 6week-old WT female. Scale bar; $50 \mu \mathrm{m}$. f RNAscope with anti-Esr1 or $\mathbf{g}$ anti-Areg probes (red) co-stained with anti-PgR antibody (green) and counterstained with DAPI (blue). Arrowheads point to apically-located luminal cells with ER $\alpha$ transcript but no PgR expression (f) and Areg transcript and PgR expression (g). Empty arrowheads point to myoepithelial cells $\mathbf{f}, \mathbf{g}$. Scale bars; $100 \mu \mathrm{m}$. $\mathbf{h}$ Current model of mammary stem cells and the differentiation hierarchy after Visvader, J.E. and Stingl, J.56. In grey: previously proposed ER $\alpha$ status of different MEC differentiation stages. In red: ER $\alpha$ status based on the present findings

with high Esr1 mRNA levels as determined by RNAscope amounted to $40 \%$ whereas the percentage of ER + cells by IHC in adjacent sections was somewhat higher with 50\% suggesting that mRNA and protein levels do not directly correlate. Whether the ERa high and ERa ${ }^{\text {low }}$ luminal cell populations that we propose correspond to the mature and progenitor sensor cells recently discerned by single cell RNA sequencing ${ }^{39,40}$ remains to be tested.

Similarly, whether the different ERa states mark distinct cell populations or reflect different transient and/or functional states of otherwise similar luminal cells, will need to be addressed by more in depth single cell sequencing. Lineage tracing experiments have shown that ERa + cells only give rise to ERa + cells $^{41,42}$. In one approach, the prominin promoter was used to drive Cre expression and shown to be expressed in a subset of ERahigh cells $^{42}$. In the other approach, a 4 -kb fragment upstream of the Esr1 transcription start site was used to drive doxycyclineinducible transgenic Cre expression; subsequently the founder was selected which showed the best overlap of Cre expression with $E R a^{\text {high }}$ cells ${ }^{41}$. It will be interesting to see how the outcome would change if the ERalow luminal cell populations were traced. If indeed would these cells give rise exclusively to ERalow luminal cells suggesting that ERa status is fixed or they may be less differentiated and more plastic and be able to give rise also to ERacells.

Furthermore, it remains to be ascertained with more sensitive quantitative approaches whether ERa status is truly tripartite in the luminal epithelium or whether underlying our observations is a continuous, possibly changing gradient in ERa expression levels.

The current model, about the cellular origin of breast cancer has it that $\mathrm{ER} \alpha+/$ luminal breast cancers originate from ER + while triple negative/basal-like breast cancers from ERa-cells. Our findings beg the question how the $\mathrm{ERa}^{\mathrm{low}}$ vs. ERa high luminal cells contribute to breast cancer development. Similarly, the current view of ERa as a marker of differentiation in a hierarchical model for mammary cell types appears too simple. At least when expressed at low levels, ERa may have an important role in controlling cell plasticity.

A picture emerges that links ERa function and signalling mechanisms to its expression level. ERa high sensor cells require both AF-1 and AF-2 to transcribe essential paracrine mediators, like Areg, Wnt4 and Pgr1 and to induce ductal growth. It is tempting to speculate that this is a means of ensuring that the strongly pro-proliferative actions of paracrine signalling only kick in when both sufficient levels of the ER ligand itself are around and growth factor signalling is simultaneously active resulting in ER phosphorylation and activation of AF-1. ERa ${ }^{\text {low }}$ responder cells largely rely on AF-2 to transcriptionally control the cytoskeleton, cell adhesion, and signalling, essential for the expansion of this cell population during ductal morphogenesis with its extensive cell movements in response to paracrine signalling. The effects of AF-1 deletion appear more subtle in the responder cells. 
We failed to detect a phenotype in the context of chimeric epithelia during ductal outgrowth, yet the $A F-1^{0}$ MECs were less efficient than their WT counterparts during intraductal engrafting suggesting that AF-1 may affect the expression of cell adhesion genes a hypothesis that seems plausible in light of the altered CD24 and CD49f expression in this mutant.

During pregnancy, $E R \alpha^{-/-}$MEC populations expand more than their WT counterparts. However, we failed to detect a difference in proliferation indices at the specific pregnancy time point we analysed, e.g., day 12.5. Two scenarios are conceivable; either at an earlier or a later time point, f.i. during alveologenesis the ER $\alpha$ MECs have higher proliferative indices than their WT counterparts, this can be addressed by more detailed follow up studies. Alternatively, pregnancy-induced cell proliferation may be faster in ERa negative MECs than in $\mathrm{ERa}^{\text {low }}$ or $\mathrm{ERa}^{\text {high }}$ cells. As only $20 \%$ of the luminal cells in the WT setting are ERa negative whereas in the $E R \alpha^{-/-}$MECs $100 \%$ lack ERa expression this could underlie the observed compensation in the course of pregnancy.

The opposite biological effects in puberty and pregnancy may also reflect a dose-dependent biphasic mode of action with low oestrogen levels in puberty and high levels during pregnancy triggering opposite actions. Alternatively, it may relate to the specific hormonal context, which changes dramatically from puberty to pregnancy, this concerns a multitude of hormones but is particularly striking for progesterone. In addition to changes in the levels of the ligands the concomitant loss of PgR expression, which opposes many ER $\alpha$ actions ${ }^{43}$ may have a role to play.

Previously, ER $\alpha$ NeoKO mice ${ }^{44}$ were suggested to be an AF-1 deficient mouse model as they transcribe a spliced mRNA that gives rise to a receptor lacking parts of the domain $\mathrm{A}$ and all domain $\mathrm{B}^{45}$. In contrast to the present finding that $E R \alpha A F-1^{0}$ mammary epithelia fail to develop alveoli, some of the $E R \alpha N e o K O$ epithelial grafts grew during pregnancy and developed alveoli ${ }^{16}$. It is conceivable that complete loss of ERa function in some MECs accounts for this; the activity of the resulting E1 ERa variant protein in the $E R \alpha N e o K O$ mice is animal and celltype dependent ${ }^{46}$.

Our finding that all ER $\alpha$ signalling is AF-2-dependent provides a molecular basis for the breast specific efficacy of the widely used breast cancer therapeutic, tamoxifen, which is an AF-2 antagonist but AF-1 agonist ${ }^{47}$.

\begin{abstract}
Methods
Mice. All mice were maintained and handled according to Swiss guidelines for animal safety with a 12-h-light-12-h-dark cycle, controlled temperature and food and water ad libitum. Animal experiments were performed in accordance with protocols approved by the Service de la Consommation et des Affaires Vétérinaires of Canton de Vaud, Switzerland. The $E R \alpha^{-/-15}, E R \alpha A F-1^{[013}, E R \alpha A F-2^{[014}$ $R A G 1^{-/-48}, C 57 B L / 6-T g(A c t-E G F P)^{27}$ and $\operatorname{tg}\left(C A G-D s R^{*}{ }^{*} M S T\right) 1 N a g y / J^{28}$ were maintained in C57Bl6 background. The NOD.Cg-Prkdcscid Il2rgtm $1 \mathrm{Wjl} / \mathrm{SzJ}$ mice $(N S G)$ were purchased from Jackson Laboratories. Mice were anaesthetised by intraperitoneal injection with $10 \mathrm{mg} / \mathrm{kg}$ xylazine and $90 \mathrm{mg} / \mathrm{kg}$ ketamine (Graeub).
\end{abstract}

Transplantations and intraductal injections. For transplantations, $1 \mathrm{~mm}^{3}$ epithelial fragments were prepared under a fluorescence stereoscope from GFP+ donor mice and inserted into the inguinal fat pads of 3-week-old $\mathrm{Rag}^{-1-}$ females cleared of their endogenous epithelium as described ${ }^{49}$. To generate chimeric epithelia, 90,000 dissociated WT.DsRed ${ }^{+}$mixed with 10,000 dissociated mutant.GFP ${ }^{+}$ cells in $10 \mu \mathrm{L}$ of $20 \%$ growth factor reduced matrigel (BD Biosciences) were injected into cleared fat pads. Mutant and control fragments were grafted into contralateral glands. The outgrowths were analysed 10 weeks after transplantation or after impregnation of the hosts on P16-18. Progesterone and control pellets were prepared as described ${ }^{50}$ and inserted subcutaneously in the neck region of 12-week-old females. Intraductal injections were performed as described ${ }^{32}$.

Mammary gland whole-mounts and image analysis. Mammary gland wholemounts were performed as described ${ }^{51}$. Stereomicrographs were acquired using a LEICA MZ FLIII stereomicroscope with Leica MC170 HD. Fluorescence images were acquired using a LEICA M205FA fluorescence stereomicroscope with Leica
DFC 340FX camera. The area of mammary fat pad filled by ducts and branching points were determined using ImageJ software. To determine the area of fat pad filled with epithelium, areas with ducts were circled using ImageJ software. The total area of the mammary fat pad, filled and not filled, was measured using the same method and the percentage of fat pad occupancy determined as ratio between duct area/total fat pad area. GFP and DsRed signal intensities were calculated with (integrated density signal - area $\left._{\text {signal }}\right) \times$ mean $_{\text {background }}$ using ImageJ software.

Immunofluorescence and antibodies. Glands were fixed with $4 \%$ paraformaldehyde overnight at $4{ }^{\circ} \mathrm{C}$ and embedded in paraffin. Sections measuring $4 \mu \mathrm{m}$ were dewaxed, rehydrated and subjected to antigen retrieval with $10 \mathrm{mM}$ trisodium citrate buffer, $\mathrm{pH} 6.0$ for $20 \mathrm{~min}$ at $95^{\circ} \mathrm{C}$. Blocking of $1 \mathrm{~h}$ with $1 \%$ BSA was followed by incubation with primary and secondary antibodies. Primary antibodies were: rabbit anti-ERa (1:100-400; MC20, sc-542 SantaCruz), rabbit anti-PR (1:400 SP2, RM-9102 Thermo Fisher Scientific), anti-SMA (1:100; RB-9010-P0; Thermo Fisher Scientific), anti-p63 (1:100; MU418-UC; BioGenex) and rabbit anti-RFP (1:400; cat\# PM005, MBL). All secondary antibodies were used at 1:500 dilutions (Molecular probes): alexa 488-conjugated anti-rabbit IgG, alexa 488-conjugated anti-goat IgG, alexa 568-conjugated anti-rabbit IgG and alexa 568-conjugated antimouse IgG. Nuclei were counterstained for $10 \mathrm{~min}$ with DAPI (Sigma) and mounted with Dabco (0718, Carl Roth). Images were acquired on confocal Zeiss LSM700 and reassembled with ImageJ software.

RNA extraction and quantitative reverse transcription polymerase chain reaction(PCR) analysis with sequencing and bioinformatics analysis. Mammary glands \#3-5 were homogenised in TRIzol (15596026, Invitrogen), total RNA was isolated using miRNeasy Micro Kit (217084, Qiagen), and cDNA synthesised with $250 \mathrm{ng}$ of total RNA using SuperScript VILO cDNA synthesis kit (11754-050 Invitrogen). For high-throughput qPCR, after a step of pre-amplification PCR using TaqMan PreAmp Master Mix kit (PN 4384556A Applied Biosystems), semiquantitative real-time PCR analysis in duplicates was performed using EvaGreen DNA-binding dye with 48.48 dynamic arrays (Fluidigm) on Biomark HD machine (Fluidigm). Primers used for the pre-amplification are composed of a mix of all primers used at a final concentration of $500 \mathrm{nM}$. Data were analysed and normalised to three housekeeping genes (Gapdh, 36B4 and Hprt) using GenEx software (MultiD). Primer sequences: Areg, ACC AAT GAG AAC TCC GCT GCT, AAG CGA TTC GCC TTT CCC TGA, 36B4, GAA CTT GCT GCA TAG CAG ACC, CTC CTT GCA ATC TCC CAG AG, Hprt, ACG AGA GGC TCA CTG CAG AC, GGA GAT TGC GGG TTT ATA ATG, $W n t-4$, AGG AGT GCC AAT ACC AGT TCC, CAG TTC TCC ACT GCT GCA TG, Prlr, GAT CAT TGT GGC CGT TCT CT, CCA GCA AGT CCT CAC AGT CA, Pgr, AAA CTG CCC AGC ATG TCG TCT, GCT CTC GTT AGG AAG GCC CA, Itgb1, TTC AGA CTT CCG CAT TGG CTT TGG, TGG GCT GGT GCA GTT TTG TTC AC, Gapdh, CCA ATG TGT CCG TCG TGG ATC, GTT GAA GTC GCA GGA GAC AAC.

RNA was extracted from GFP + FACS-sorted cells using miRNeasy Mini Kit (Qiagen). Libraries were prepared in two steps. The first step was performed with SMART-Seq v4 ultra low input RNA Kit (Clontech). Briefly, 10 ng of RNA was reverse transcribed using a oligo dT primer flanked with a proprietary adaptor. Template switching mechanism was then used to append another proprietary adaptor on the $3^{\prime}$ end of the cDNA corresponding to the beginning of the mRNA molecule. A PCR specific for the aforementioned adaptors was used to create and amplify double-stranded cDNA molecules. The second step was performed with Nextera XT kit (Illumina). Briefly, tagmentation of the double-stranded CDNA with hyperactive $\operatorname{Tn} 5$ created fragments of a few hundred bp, flanked with Illumina proprietary adaptors. DNA was then PCR amplified with Illumina primers for eight cycles, generating final libraries of $\sim 400 \mathrm{bp}$ (insert plus adaptors). Libraries were sequenced on Illumina NextSeq 500 instrument with single-end reads of 85nt. Base calls and Illumina adaptors trimming performed using bcl2fastq v2.18. Clontech adaptors trimming performed with CLC 9. RNAseq reads were aligned to the mm10 genome assembly using the web application HTSstation ${ }^{52}$. For the differential RNAseq expression analysis we applied the automated analysis pipeline ASAP $^{53}$ for $90 \%$ top expressed threshold (\% of genes kept in the data frame). Lists of $\mathrm{DE}$ analyses were performed using edgeR package. Heatmap was generated using ClustVist $^{54}$

RNA in situ hybridisation. RNAscope assay (Advanced Cell Diagnostics, Cat. No. 323110) was performed according to manufacturer's protocol on $4 \mu \mathrm{m}$ deparaffinized sections and hybridised with probes: Mm-Esr1 (ACD, Cat. No. 432861), Mm-Areg (ACD, Cat. No. 430501), Mm-Ppib (ACD, Cat. No. 313911, positive control) and DapB (ACD, Cat. No. 310043, negative control) at $40^{\circ} \mathrm{C}$ for $2 \mathrm{~h}$ and revealed with TSA Plus-Cy3 (Perkin Elmer, Cat. No. NEL744001KT). Rabbit antiPgR (1:400, clone SP2, Thermo Fisher, Cat. No.: RM-9102-P) and rabbit anti-ERa (1:100; MC20, sc-542 SantaCruz) was incubated overnight at $4{ }^{\circ} \mathrm{C}$ and detected with Alexa 488 or Alexa 568 conjugated goat anti-rabbit (1:1000, Life Technology), respectively. Images were captured on confocal Zeiss LSM700 and spots quantified using QuPath and an in-house script, code available from O. Burri at the Bioimaging and Optics platform, EPFL, based on the guide for RNAscope Data Analysis. 
Hormone measurements. Testosterone, androstenedione, 17a-hydroxyprogesterone, corticosterone, 11-deoxycorticosterone and progesterone levels were measured by LC-MS High Resolution (Q-Exactive, ThermoFisher Scientific). Frozen plasma samples were thawed, vortex mixed, centrifuged at $33,000 \mathrm{~g}$ for $5 \mathrm{~min}$. An aliquot of $50-100 \mu \mathrm{L}$ was spiked with $10 \mu \mathrm{L}$ of internal standards. After diluting the samples with $5 \%(\mathrm{w} / \mathrm{v})$ phosphoric acid, the analytes were purified using a solid phase extraction (Oasis MCX 96-well plate, Waters). The washing steps were $5 \%(\mathrm{w} / \mathrm{v}) \mathrm{NH}_{4} \mathrm{OH}$ and $20 \%(\mathrm{v} / \mathrm{v})$ methanol. The separation column was an Acquity UPLC HSS T3 column $(1.8 \mu \mathrm{m}, 1.0 \times 100 \mathrm{~mm}$, Waters), the mobile phase comprised $\mathrm{H}_{2} \mathrm{O}$ and $0.01 \%$ formic acid in methanol. The liquid chromatography system was coupled to a Q-Exactive Orbitrap mass spectrometer (Thermo Scientific) using a full scan acquisition. The calibrants were certified standards (ChromSystems). Estradiol was extracted from 100 to $200 \mu \mathrm{L}$ plasma with ethyl acetate: hexane (3:2). The upper organic layer was evaporated under nitrogen followed by derivatization with dansyl chloride. The separative column was a Zorbax Eclipse Plus RRHD C18 (Agilent); analysis was carried out on a 6495 Triple Quad LC/MS-MS (Agilent) ${ }^{55}$.

Fluorescence activated cell sorting. Mammary glands were pooled for the preparation of single cell suspensions and processed for flow cytometry as described ${ }^{34}$. The following conjugated antibodies were used: anti-CD24-PE-Cy7 (560536, BD Pharmingen), anti-CD49f-APC (313616, Biolegend), anti-CD31-BV421 (563356, BD Pharmingen), anti-CD45-BV421 (563890, BD Pharmingen) and anti-Ter119BV421 (563998, BD Pharmingen). Mammary epithelial cells were sorted on a FACSAria flow cytometer (Becton Dickinson) or analysed on LSRII flow cytometer analyser (Becton Dickinson).

Statistical analysis. Statistical analyses were performed with Prism7 software (GraphPad). Data are shown as means \pm SD, or as otherwise specified. Statistical significance is indicated as follows ${ }^{*} p<0.05,{ }^{* *} p<0.01,{ }^{* * *} p<0.001,{ }^{* * *} p<0.0001$, n.s. not significant.

\section{Data availability}

The transcriptomics data have been deposited in the Gene Expression Omnibus database under accession code GSE103664;

Received: 26 March 2018 Accepted: 15 October 2018

Published online: 09 November 2018

\section{References}

1. Zeps, N., Bentel, J. M., Papadimitriou, J. M., D’Antuono, M. F. \& Dawkins, H. J. Estrogen receptor-negative epithelial cells in mouse mammary gland development and growth. Differentiation 62, 221-226 (1998).

2. Brisken, C. \& O'Malley, B. Hormone action in the mammary gland. Cold Spring Harb. Perspect. Biol. 2, a003178 (2011).

3. Kumar, V. et al. Functional domains of the human estrogen receptor. Cell $\mathbf{5 1}$, 941-951 (1987)

4. Krust, A. et al. The chicken oestrogen receptor sequence: homology with verbA and the human oestrogen and glucocorticoid receptors. EMBO J. 5, 891-897 (1986).

5. Tora, L. et al. The human estrogen receptor has two independent nonacidic transcriptional activation functions. Cell 59, 477-487 (1989).

6. Kato, S. et al. Activation of the estrogen receptor through phosphorylation by mitogen-activated protein kinase. Science 270, 1491-1494 (1995).

7. Medunjanin, S. et al. Glycogen synthase kinase- 3 interacts with and phosphorylates estrogen receptor alpha and is involved in the regulation of receptor activity. J. Biol. Chem. 280, 33006-33014 (2005).

8. Rogatsky, I., Trowbridge, J. M. \& Garabedian, M. J. Potentiation of human estrogen receptor alpha transcriptional activation through phosphorylation of serines 104 and 106 by the cyclin A-CDK2 complex. J. Biol. Chem. 274, 22296-22302 (1999).

9. Marino, M., Galluzzo, P. \& Ascenzi, P. Estrogen signaling multiple pathways to impact gene transcription. Curr. Genom. 7, 497-508 (2006).

10. Arnal, J.-F. et al. Membrane and nuclear estrogen receptor alpha actions: from tissue specificity to medical implications. Physiol. Rev. 97, 1045-1087 (2017).

11. Levin, E. R. \& Hammes, S. R. Nuclear receptors outside the nucleus: extranuclear signalling by steroid receptors. Nat. Rev. Mol. Cell Biol. 17, 783-797 (2016).

12. Fontaine, C. et al. Tamoxifen elicits atheroprotection through estrogen receptor alpha AF-1 but does not accelerate reendothelialization. Am. J. Pathol. 183, 304-312 (2013).

13. Billon-Galés, A. et al. The transactivating function 1 of estrogen receptor alpha is dispensable for the vasculoprotective actions of 17beta-estradiol. Proc. Natl Acad. Sci. USA 106, 2053-2058 (2009).
14. Billon-Galés, A. et al. Activation function 2 (AF2) of estrogen receptor-alpha is required for the atheroprotective action of estradiol but not to accelerate endothelial healing. Proc. Natl Acad. Sci. USA 108, 13311-13316 (2011).

15. Dupont, S. et al. Effect of single and compound knockouts of estrogen receptors alpha (ERalpha) and beta (ERbeta) on mouse reproductive phenotypes. Development 127, 4277-4291 (2000).

16. Mallepell, S., Krust, A., Chambon, P. \& Brisken, C. Paracrine signaling through the epithelial estrogen receptor alpha is required for proliferation and morphogenesis in the mammary gland. Proc. Natl Acad. Sci. USA 103, 2196-2201 (2006)

17. Börjesson, A. E. et al. Roles of transactivating functions 1 and 2 of estrogen receptor-alpha in bone. Proc. Natl Acad. Sci. USA 108, 6288-6293 (2011).

18. DeOme, K. B., Faulkin, L. J. Jr, Bern, H. A. \& Blair, P. B. Development of mammary tumors from hyperplastic alveolar nodiles transplanted into glandfree mammary fat pads of female C3H mice. Cancer Res. 19, 511-520 (1959).

19. Ciarloni, L., Mallepell, S. \& Brisken, C. Amphiregulin is an essential mediator of estrogen receptor alpha function in mammary gland development. Proc. Natl Acad. Sci. USA 104, 5455-5460 (2007).

20. Sternlicht, M. D. et al. Mammary ductal morphogenesis requires paracrine activation of stromal EGFR via ADAM17-dependent shedding of epithelial amphiregulin. Development 132, 3923-3933 (2005).

21. Rajaram, R. D. et al. Progesterone and Wnt 4 control mammary stem cells via myoepithelial crosstalk. EMBO J. 34, 641-652 (2015).

22. Haslam, S. \& Shyamala, G. Effect of oestradiol on progesterone receptors in normal mammary glands and its relationship with lactation. Biochem. J. 182, p127-p131 (1979)

23. Leondires, M. P., Hu, Z. Z., Dong, J., Tsai-Morris, C. H. \& Dufau, M. L. Estradiol stimulates expression of two human prolactin receptor isoforms with alternative exons-1 in T47D breast cancer cells. J. Steroid Biochem. Mol. Biol. 82, 263-268 (2002).

24. Brisken, C. \& Duss, S. Stem cells and the stem cell niche in the breast: an integrated hormonal and developmental perspective. Stem. Cell Rev. 3, 147-156 (2007).

25. Brisken, C. Progesterone signalling in breast cancer: a neglected hormone coming into the limelight. Nat. Rev. Cancer 13, 385-396 (2013).

26. Stingl, J. et al. Purification and unique properties of mammary epithelial stem cells. Nature 439, 993-997 (2006).

27. Okabe, M., Ikawa, M., Kominami, K., Nakanishi, T. \& Nishimune, Y. “Green mice" as a source of ubiquitous green cells. FEBS Lett. 407, 313-319 (1997).

28. Vintersten, K. et al. Mouse in red: red fluorescent protein expression in mouse ES cells, embryos, and adult animals. Genesis 40, 241-246 (2004).

29. Chung, E., Yeung, F. \& Leinwand, L. A. Akt and MAPK signaling mediate pregnancy-induced cardiac adaptation. J. Appl. Physiol. 112, 1564-1575 (2012).

30. Beleut, M. et al. Two distinct mechanisms underlie progesterone-induced proliferation in the mammary gland. Proc. Natl Acad. Sci. USA 107, 2989-2994 (2010)

31. Ismail, P. M., Li, J., DeMayo, F. J., O’Malley, B. W. \& Lydon, J. P. A novel LacZ reporter mouse reveals complex regulation of the progesterone receptor promoter during mammary gland development. Mol. Endocrinol. 16, 2475-2489 (2002)

32. Sflomos, G. et al. A preclinical model for ERalpha-positive breast cancer points to the epithelial microenvironment as determinant of luminal phenotype and hormone response. Cancer Cell 29, 407-422 (2016).

33. Shackleton, M. et al. Generation of a functional mammary gland from a single stem cell. Nature 439, 84-88 (2006).

34. Kendrick, H. et al. Transcriptome analysis of mammary epithelial subpopulations identifies novel determinants of lineage commitment and cell fate. BMC Genom. 9, 591 (2008).

35. Fabregat, A. et al. The reactome pathway knowledgebase. Nucleic Acids Res. 46, D649-D655 (2018).

36. Nikolova, Z., Djonov, V., Zuercher, G., Andres, A. C. \& Ziemiecki, A. Celltype specific and estrogen dependent expression of the receptor tyrosine kinase EphB4 and its ligand ephrin-B2 during mammary gland morphogenesis. J. Cell Sci. 111, 2741-2751 (1998).

37. Lu, P., Ewald, A. J., Martin, G. R. \& Werb, Z. Genetic mosaic analysis reveals FGF receptor 2 function in terminal end buds during mammary gland branching morphogenesis. Dev. Biol. 321, 77-87 (2008).

38. Subramanian, A. et al. Gene set enrichment analysis: a knowledge-based approach for interpreting genome-wide expression profiles. Proc. Natl Acad. Sci. USA 102, 15545-15550 (2005).

39. Bach, K. et al. Differentiation dynamics of mammary epithelial cells revealed by single-cell RNA sequencing. Nat. Commun. 8, 2128 (2017).

40. Pal, B. et al. Construction of developmental lineage relationships in the mouse mammary gland by single-cell RNA profiling. Nat. Commun. 8, 1627 (2017)

41. Van Keymeulen, A. et al. Lineage-restricted mammary stem cells sustain the development, homeostasis, and regeneration of the estrogen receptor positive lineage. Cell Rep. 20, 1525-1532 (2017). 
42. Wang, C., Christin, J. R., Oktay, M. H. \& Guo, W. Lineage-biased stem cells maintain estrogen-receptor-positive and -negative mouse mammary luminal lineages. Cell Rep. 18, 2825-2835 (2017).

43. Mohammed, H. et al. Progesterone receptor modulates ERalpha action in breast cancer. Nature 523, 313-317 (2015).

44. Lubahn, D. et al. Alteration of reproductive function but not prenatal sexual development after insertional disruption of the mouse estrogen receptor gene. Proc. Natl Acad. Sci. USA 90, p11162-p11166 (1993).

45. Couse, J. F. et al. Estrogen receptor-alpha knockout mice exhibit resistance to the developmental effects of neonatal diethylstilbestrol exposure on the female reproductive tract. Dev. Biol. 238, 224-238 (2001).

46. Kos, M., Denger, S., Reid, G., Korach, K. S. \& Gannon, F. Down but not out? A novel protein isoform of the estrogen receptor alpha is expressed in the estrogen receptor alpha knockout mouse. J. Mol. Endocrinol. 29, 281-286 (2002).

47. McDonnell, D. P., Clemm, D. L., Hermann, T., Goldman, M. E. \& Pike, J. W. Analysis of estrogen receptor function in vitro reveals three distinct classes of antiestrogens. Mol. Endocrinol. 9, 659-669 (1995).

48. Mombaerts, P. et al. RAG-1-deficient mice have no mature B and T lymphocytes. Cell 68, p869-p877 (1992).

49. Brisken, C. et al. A paracrine role for the epithelial progesterone receptor in mammary gland development. Proc. Natl Acad. Sci. USA 95, 5076-5081 (1998).

50. Duss, S. et al. An oestrogen-dependent model of breast cancer created by transformation of normal human mammary epithelial cells. Breast Cancer Res. 9, R38 (2007).

51. Ayyanan, A. et al. Perinatal exposure to bisphenol A increases adult mammary gland progesterone response and cell number. Mol. Endocrinol. 25, 1915-1923 (2011).

52. David, F. P. A. et al. HTSstation: a web application and open-access libraries for high-throughput sequencing data analysis. PLoS ONE 9, e85879 (2014).

53. Gardeux, V., David, F. P. A., Shajkofci, A., Schwalie, P. C. \& Deplancke, B. ASAP: a web-based platform for the analysis and interactive visualization of single-cell RNA-seq data. Bioinformatics 33, 3123-3125 (2017)

54. Metsalu, T. \& Vilo, J. ClustVis: a web tool for visualizing clustering of multivariate data using principal component analysis and heatmap. Nucleic Acids Res. 43, W566-W570 (2015).

55. Bruce, S. J. et al. Discrepancy between radioimmunoassay and high performance liquid chromatography tandem-mass spectrometry for the analysis of androstenedione. Anal. Biochem. 455, 20-25 (2014).

56. Visvader, J. E. \& Stingl, J. Mammary stem cells and the differentiation hierarchy: current status and perspectives. Genes Dev. 28, 1143-1158 (2014).

\section{Acknowledgements}

We thank J. Dessimoz and O. Burri for advice on RNAscope and the EPFL core facilities for technical assistance, N. Hynes, F. Lenfant and Brisken laboratory members for reading of the manuscript, R. Jeitziner for help with the bioinformatic analysis. S.C., D.A. and V.S. received funding from the Swiss Cancer Ligue KFS-3701-08-2015 and SNF 31003A_162550/1 Hormonal and cell signaling control of mammary gland morphogenesis: The role of Adamts18 in epithelial-basal membrane interactions that control the stem cell function downstream of progesterone receptor signaling, G.S. and P.A. by Biltema and ISREC Foundation.

\section{Author contributions}

Investigation: S.C., D.A., G.S., S.S., P.A., A.A. and V.S. Bioinformatic analysis: G.S Resources: H.H., A.K., P.C. and M.F. Writing: S.C. and C.B. Funding acquisition: C.B.

\section{Additional information}

Supplementary Information accompanies this paper at https://doi.org/10.1038/s41467 018-07175-0.

Competing interests: The authors declare no competing interests.

Reprints and permission information is available online at http://npg.nature.com/ reprintsandpermissions/

Publisher's note: Springer Nature remains neutral with regard to jurisdictional claims in published maps and institutional affiliations.

(c) (i) Open Access This article is licensed under a Creative Commons Attribution 4.0 International License, which permits use, sharing, adaptation, distribution and reproduction in any medium or format, as long as you give appropriate credit to the original author(s) and the source, provide a link to the Creative Commons license, and indicate if changes were made. The images or other third party material in this article are included in the article's Creative Commons license, unless indicated otherwise in a credit line to the material. If material is not included in the article's Creative Commons license and your intended use is not permitted by statutory regulation or exceeds the permitted use, you will need to obtain permission directly from the copyright holder. To view a copy of this license, visit http://creativecommons.org/ licenses/by/4.0/.

(C) The Author(s) 2018 